Archived version from NCDOCKS Institutional Repository http://libres.uncg.edu/ir/asu/

\title{
Appalachỉan
}

B O O N E, N O R T H C A R O L I N A

\section{Rationality And Forecasting Accuracy Of Exchange Rate Expectations: Evidence From Survey-Based Forecasts}

\author{
By: Onur Ince \& Tanya Molodtsova
}

\begin{abstract}
We examine rationality, forecasting accuracy, and economic value of the survey-based exchange rate forecasts for 10 developed and 23 developing countries at the 3-, 12-, and 24-month horizons. Using the data from two surveys for the period from 2004 to 2012, we find strong evidence that the forecasts for developing countries are biased at all forecast horizons. For developed countries, forecasts are strongly biased at the 3-month horizon, the bias decreases at the 12month horizon, and increases again at the 24-month horizon. Based on the magnitude of the forecast errors and the direction of change, long-term forecasts are more accurate than short-term forecasts. Economic evaluation of the forecasts indicates that the forecasters are successful at generating positive economic profits, and economic gains of the forecasts for developed countries improve with the forecast horizon.
\end{abstract}

Ince, O. and T. Molodtsova (2017). "Rationality and forecasting accuracy of exchange rate expectations: Evidence from survey-based forecasts." Journal of International Financial Markets, Institutions and Money 47: 131-151. https:// doi.org/10.1016/j.intfin.2016.11.002. Publisher version of record available: https://www.sciencedirect.com/science/article/pii/S1042443116301536 


\title{
Rationality and forecasting accuracy of exchange rate expectations: Evidence from survey-based forecasts
}

\author{
Onur Ince, Tanya Molodtsova* \\ Department of Economics, Appalachian State University, Boone, NC 28608, United States
}

\begin{abstract}
A B S T R A C T
We examine rationality, forecasting accuracy, and economic value of the survey-based exchange rate forecasts for 10 developed and 23 developing countries at the 3-, 12-, and 24-month horizons. Using the data from two surveys for the period from 2004 to 2012, we find strong evidence that the forecasts for developing countries are biased at all forecast horizons. For developed countries, forecasts are strongly biased at the 3-month horizon, the bias decreases at the 12-month horizon, and increases again at the 24-month horizon. Based on the magnitude of the forecast errors and the direction of change, long-term forecasts are more accurate than short-term forecasts. Economic evaluation of the forecasts indicates that the forecasters are successful at generating positive economic profits, and economic gains of the forecasts for developed countries improve with the forecast horizon.
\end{abstract}

\section{Introduction}

Exchange rate expectations play an important role in the literature on exchange rate determination. Understanding how exchange rate expectations are formed is crucial for both academic analysis and decision-making of practitioners and policymakers. Models of exchange rate determination in open-economy macroeconomics often rely on the assumption of the rationality of expectations. ${ }^{1}$ In the absence of survey-based expectations, it is practically impossible to test the implications of theoretical exchange rate models, without running into a problem of joint hypothesis testing. For example, the uncovered interest parity (UIP), the condition that the expected exchange rate depreciation must equal the interest rate differential between the two countries, is typically tested assuming rational expectations because the expected exchange rate changes are unobservable. In the absence of survey-based expectations, the expected exchange rate depreciation is typically replaced with actual ex-post realizations of the exchange rate. Thus, testing the uncovered interest parity involves testing the combined assumption of no risk premium (or the validity of the UIP) and rational expectations. ${ }^{2}$ Testing the rationality of market expectations helps to assess the validity of the rational expectations hypothesis and accurately interpret empirical results in similar

\footnotetext{
* Corresponding author.

E-mail addresses: inceo@appstate.edu (O. Ince), molodtsovat@appstate.edu (T. Molodtsova).

1 Engel (1996) and Lewis (1995) survey the literature on studies that examine puzzles in foreign exchange rate markets assuming rational expectations.

2 This joint hypothesis, sometimes referred to as the risk-neutral efficient-markets hypothesis (RNEMH), is reviewed and tested with and without surveybased data in Chinn (2006).
} 
studies. In addition, it has been shown that the rationality assumption can have serious implications for evaluating the effectiveness of macroeconomic policies.

While the forecasts of macroeconomic variables have been studied for at least sixty years, the literature on survey-based exchange rate expectations goes back only to the late 1980s. Limited data availability and proprietary nature of the data are mainly responsible for short history of research on professional exchange rate forecasts. Following Dominguez (1986) and Frankel and Froot (1987), other studies have examined the nature of exchange rate expectations using survey data. Jongen et al. (2008) highlight five main issues in the literature on the role of exchange rate expectations: the forward discount puzzle, rationality of expectations, time-varying risk premium, heterogeneity of expectations, and forecasting accuracy of professional forecasters. In this paper, we focus our analysis on the rationality, predictive accuracy, and economic evaluation of survey-based exchange rate forecasts.

The rationality of exchange rate expectations is typically tested empirically by verifying whether the unbiasedness and orthogonality conditions are met. $^{3}$ Overall, previous studies tend to find evidence of irrationality and no predictive ability of professional exchange rate forecasts. For example, Dominguez (1986), Frankel and Froot (1987), Avraham et al. (1987), Cavaglia et al. (1993), Chinn and Frankel (1994), MacDonald and Marsh (1994), and more recently Cavusoglu and Neveu (2015) test whether survey-based exchange rate expectations are biased in a regression of the actual depreciation on the expected depreciation. In a review article, Jongen et al. (2008) conclude that the hypothesis of unbiasedness is rejected "for nearly all currencies and forecast horizons". Takagi (1991), MacDonald (2000), and Jongen et al. (2008) summarize the literature on survey-based expectations and report that exchange rate expectations are not rational and have low forecasting ability.

Previous studies on the rationality of exchange rate expectations focus almost exclusively on the developed countries. The exceptions are Frankel and Chinn (1993), who use 3- and 12-month forecasts from Currency Forecasters' Digest for 17 countries (15 of which are developed) to study the relative role of time-varying risk premium and rational expectations for the forward discount bias, and Chinn and Frankel (1994, 2002), who study survey-based expectations for a set of 24 countries (that includes 14 advanced economies) at the same forecast horizons as Frankel and Chinn (1993), and find less bias for minor currencies than for major currencies. ${ }^{4}$

There are three main differences between our approach to testing for rationality of exchange rate expectations and that of the earlier studies. First, we substantially expand the list of emerging economies in our sample. Using survey data on 23 emerging countries and 10 developed countries, we identify new patterns in the behavior of exchange rate forecasts for the two groups of countries that have considerable volatility differences. Another notable difference is that our sample includes the Euro/U.S. dollar forecasts instead of the European Monetary System (EMS) countries individually. Second, in addition to Currency Forecasters' Digest, currently known as FX4Casts, we analyze survey-based expectations for the same 33 countries from Consensus Economics dataset. Third, we estimate the regressions for 3-, 12-, and 24-month ahead forecasts country-by-country instead of pooling forecasts across a diverse group of countries as in many earlier studies. We focus on the period between January 2004 and December 2012. Using the longest available sample period for all currencies and all forecast horizons in both datasets, we compare the results between different forecast horizons, different currencies, and two data providers. ${ }^{5}$

Using two datasets allows us to study two sets of forecasts that are produced by different samples of respondents. While Consensus Economics surveys a wider sample of respondents that includes investment banks, large non-financial enterprises, consulting firms, and university economists, FX4Casts sample includes only large financial institutions that might have stronger incentives to provide accurate forecasts and, thus, could provide a superior representation of the behavior of market participants. Thus, we are able to assess the robustness of the results and extract additional insights into the behavior of market participants.

In order to assess the rationality of exchange rate expectations, we use conventional tests for unbiasedness and orthogonality. Overall, we find the evidence that the null of unbiasedness is strongly rejected at all three forecast horizons for developing countries. For developed countries, we find that the forecast bias has a nonlinear relationship with the forecast horizon. Survey forecasts for developed countries are strongly biased at the 3-month horizon, the forecast bias decreases at the 12-month horizon, and increases again at the 24-month horizon. Cavusoglu and Neveu (2015) consider 5 major currencies in FX4Casts and find that the forecasts mostly appear to be unbiased in the long run, but are biased in the short run. Our results confirm their findings in the short run, but show that the forecast bias increases substantially at longer forecast horizons. We also test for the orthogonality of forecast errors using 2 different criteria, to analyze the efficiency of exchange rate forecasts. Orthogonality tests reveal that professional forecasters in FX4Casts are very efficient at the short forecast horizon.

\footnotetext{
${ }^{3}$ Pesaran (1987) specifies four conditions of rationality: unbiasedness, orthogonality of the forecast errors to variables in the information set available to market participants, serial correlation in the forecast errors only up to order $h-1$, and orthogonality of the forecast errors to past variables that are expected to form the expectations. We focus on the former two conditions, which are conventionally tested in the literature. Since we use aggregate forecasts, we cannot test the serial correlation condition because we are unable to control for heterogeneity across forecasters, which might introduce serial correlation in the forecast errors. The last condition requires the knowledge of the information set of survey participants, which we do not have.

${ }^{4}$ Frankel and Poonawala (2010) replace exchange rate expectations with realized exchange rates for 21 developed and 14 developing countries from 1996 to 2004 and confirm that the forward rate is a less biased predictor of the future exchange rate in emerging market currencies than in advanced economies. Bansal and Dahlquist (2000) find that the uncovered interest parity puzzle is limited only to developed countries and the situations where the interest rate differential is positive.

${ }^{5}$ The results using the longest sample period for each individual country are available from the authors upon request.
} 
As the horizon increases to 12 months, the forecast efficiency is strongly rejected for developed countries, while the forecasts for developing countries are relatively more efficient.

After testing the rationality of survey-based forecasts, we evaluate the forecasting performance of professional forecasters. This is the first paper that studies the predictive accuracy of survey-based exchange rate expectations for developing and advanced countries. Those few studies that assess the accuracy of professional exchange rate forecasts, in general, find no evidence that the expectations can outperform the random walk, or a naïve no-change forecast. For example, MacDonald and Marsh $(1994,1996)$ calculate the root mean squared errors (RMSEs) for 30 individual forecasters of the British pound, the Deutsche mark, and the Japanese yen vis-a-vis the U.S. dollar for the period 1989-1991 and find that only 2 out of 30 forecasters outperform the random walk. Mitchell and Pearce (2007) confirm this finding for the WSJ forecasts of the Yen/U.S. dollar exchange rate.

We apply two statistical evaluation methods to assess the forecasting ability of survey-based exchange rate forecasts at different forecast horizons for the two groups of countries. The first approach is based on the differences between the mean squared prediction errors (MSPEs) of the forecasts and the random walk, and the second is focused on the direction-ofchange comparison, where the forecasts are evaluated based on their ability to correctly predict the direction of the exchange rate movements. Since developing countries are more likely to suffer from short spells of high inflation and interest rates, political instabilities, and capital flights, their currencies are prone to sudden changes in one direction. As a result, it might be easier for professional forecasters to predict the direction of exchange rate change for developing than for developed countries. ${ }^{6}$

We use the Diebold and Mariano (1995) and West (1996) tests (henceforth, DMW tests) for equal forecasting ability of survey forecasts and the random walk without drift to examine the predictive accuracy of exchange rate forecasts based on the MSPE comparisons. ${ }^{7}$ In addition to the MSPE-based tests, we use Pesaran and Timmermann (1992) test for the directional forecast accuracy to evaluate the ability of the forecasters to correctly predict the direction of exchange rate movements. Another advantage of using the direction of change tests is that they do not impose any restrictions on the functional form of the forecasting model and allow for non-linearities. ${ }^{8}$ The results of the forecasting accuracy tests indicate that the performance of survey-based forecasts improves with the forecast horizon for both groups of countries. While the evidence of forecasting ability is weak at the 3-month horizon, it improves significantly at the 12 and 24-month horizons for both groups of countries.

To determine whether the forecasters are successful at generating positive economic gains, we assess the economic value of survey-based forecasts based on the Directional Value statistic developed by Blaskowitz and Herwartz (2011) and the Sharpe ratio. The former allows us to take into account both directional accuracy and predictive accuracy when evaluating economic gains of the forecasts, while the latter calculates the risk-adjusted excess returns. Overall, the results indicate that the forecasters are successful at generating positive economic profits. The mean Directional Value statistic is larger for developing than for developed countries at all forecast horizons. As with the evidence of forecasting accuracy, both economic value statistics for developed countries increase on average with the forecast horizon. Overall, the survey-based forecasts are more successful based on the economic evaluation than the statistical evaluation of their performance.

\section{Survey data}

We use the data on professional exchange rate forecasts from two data sources: FX4Casts, which was previously known as The Financial Times Currency Forecaster and Currency Forecasters' Digest, and Consensus Economics. Both datasets contain exchange rate forecasts for the same 9 developed countries (Australia, Canada, Denmark, Japan, New Zealand, Norway, Sweden, Switzerland, and the U.K.) plus the Euro Area. In addition to 10 advanced economies, both datasets include the exchange rate forecasts for 23 emerging markets. The survey data cover the period from January 2004 to December 2012. This is the longest available sample period for all currencies and all forecast horizons in both datasets, which allows us to achieve comparability of the results between different forecast horizons, different currencies, and the two data providers.

We have excluded from the analysis some countries with tightly fixed exchange rates. Following Frankel and Poonawala (2010), we did not exclude currencies that have relatively stable exchange rates or operate under capital controls. Although some of the included currencies operate under de jure stabilizing arrangement relative to one currency or a basket of currencies, a sufficient amount of movement is allowed for all of the included currencies.

Monthly forecasts in the survey data are the geometric mean of the individual responses, which minimizes the effect of the extreme forecasts. Unfortunately, individual forecasts of each respondent are not available, which makes it impossible for us to test for heterogeneity of forecasts and explore other characteristics of individual forecasters. Bonham and Cohen (2001) show that the use of consensus forecasts may lead to false acceptance of the unbiasedness hypothesis in the presence

\footnotetext{
${ }^{6}$ Since a random walk forecast is a no-change forecast, sudden movements in the exchange rates increase the prediction error of the random walk and lead to more rejections of the null of equal forecasting ability.

7 Since Meese and Rogoff (1983), evaluating exchange rate forecasts relative to the random walk benchmark has become a standard in the literature. We choose a more conservative benchmark of a random walk without drift that is more difficult to outperform, in order to reduce the possibility of finding spurious evidence of forecasting power.

${ }^{8}$ See for example, Keane and Runkle (1990) and Bonham and Cohen (2001).
} 
of heterogeneity. Therefore, in addition to the unbiasedness tests, we use two alternative rationality tests that are based on the orthogonality conditions to obtain more robust inference. ${ }^{9}$

Consensus Economics dataset contains 3-, 12-, and 24-month ahead exchange rate forecasts that are produced via a monthly survey of over 250 forecasters. The number of responders (typically around 30) varies across currencies and time periods. ${ }^{10}$ The sample of forecasters includes investment banks, large non-financial enterprises, consulting firms, and university economists. The survey is usually conducted on the second Monday of every month. In addition to the forecasts of the exchange rate change at the 3,12, and 24 months ahead horizon, Consensus Economics reports the level of the spot exchange rate on the date of the forecast, or a nowcast. We include 24-month ahead exchange rate forecasts that are only available in Consensus Economics dataset for our sample period, because previous studies have rarely considered forecasts beyond 12-month horizon.

In addition to Consensus Economics dataset, we use 3- and 12-month ahead forecasts of the same 33 currencies vis-à-vis the U.S. dollar from FX4Casts. Consensus Economics dataset provides a comprehensive coverage of developed and developing countries, and has not been extensively studied in the literature yet. However, the sample of its respondents includes business firms and academicians, who might not have strong incentives to provide accurate forecasts. To mitigate this issue, we include FX4Casts dataset that focuses exclusively on the financial markets. Although the dataset contains forecasts for other developing countries, we have restricted the sample to the countries that are common in both datasets. FX4Casts puts an emphasis on the reliability of their forecasts by surveying 45 large financial institutions. ${ }^{11}$ The survey is usually conducted on the last Thursday of each month by email (or fax), with the responses being returned during Friday and the following Monday and Tuesday. As Consensus Economics, FX4Casts also provides the current level of the spot exchange rate.

\section{Summary statistics}

We start by examining summary statistics of the actual depreciation, expected exchange rate depreciation, and forecast errors for 3-, 12-, and 24-month ahead forecasts in both datasets. Tables 1 and 2 contain the mean and standard deviation of the actual and expected exchange rate depreciation of the foreign currency relative to the U.S. dollar. Table 3 reports the mean and standard deviation of the forecast errors. In all tables, Panel A reports the statistics for 10 developed countries, and Panel B provides the results for 23 developing countries. Overall, four main patterns are apparent from the results.

First, the absolute value of the mean of expected depreciation in Table 2 increases with the forecast horizon. This empirical finding is consistent with the results reported by Dominguez (1986), Frankel and Froot (1987), and MacDonald and Torrance (1990). The number of departures from this empirical regularity is larger for developed than developing countries. Among the developing countries, only India exhibits a declining mean of expected depreciation at the 24-month horizon in Consensus Economics dataset and only Bolivia at the 12-month horizon in FX4Casts. For developed countries, the pattern is violated for 4 out of 10 countries in Consensus Economics forecasts (for Japan, and the U.K. at the 12-month horizon, and for Norway and Switzerland at the 24-month horizon), and for 2 out of 10 countries in FX4Casts data (for Australia and Denmark at the 12-month horizon). Thus, the forecasters do not believe that the exchange rates follow a mean-reverting process. If survey respondents believed in the validity of the hypothesis that the nominal exchange rate returns to its fundamental value within 24 months as in Mark (1995), the absolute value of the mean of expected depreciation would decrease with the forecast horizon. The mean of the actual depreciation in Table 1 also increases with the forecast horizon, supporting the forecasters' expectations. This result is consistent with the idea that it takes longer than 24 months for the exchange rate to display mean-reversion. For example, Mark (1995), Engel et al. (2008), and Ince (2014) find strong evidence of exchange rate predictability with conventional exchange rate models only at the 16-quarter horizon.

Second, the standard deviation of the expected and actual depreciation in Tables 1 and 2 increases with the forecast horizon as well. For expected depreciation, this pattern is violated only for 24-month ahead forecasts from Consensus Economics for Mexico and Singapore. For the actual depreciation, the exceptions are for Canada, Norway, Switzerland, Colombia, Peru, and Uruguay at the 24-month ahead forecast horizon. Third, both the absolute mean and standard deviation of the forecast errors reported in Table 3 increase with the forecast horizon. ${ }^{12}$ This result is in accord with Dominguez (1986), who finds that 1-week and 2-week ahead forecasts of major currencies have smaller standard deviations than 1-month and 3-month ahead forecasts. Similarly, Frankel and Froot (1987) report the same empirical finding for 3-, 6-, and 12-month ahead major currency expectations from the Economist survey.

Fourth, comparing the results in Tables 1 and 2, we can see that in general the standard deviation of the actual depreciation is larger than that of the expected depreciation, while the pattern for the absolute value of the mean actual depreci-

\footnotetext{
${ }^{9}$ While one could argue that individual forecasts are preferable when testing for rationality, Aiolfi et al. (2011) show that aggregating individual forecasts could generate more accurate forecasts.

${ }^{10}$ Total number of survey respondents and the number of forecasters are taken from the Consensus Economics website: http://www.consensuseconomics.com/forex_major.htm.

${ }^{11}$ Total number of participating institutions and respondents are taken from FX4Casts website: http://www.FX4Casts.com.

12 For the mean, the pattern is violated at the 12-month horizon for Bangladesh and Mexico, and at the 24-month horizon for Sweden, Argentina, India, and Indonesia. All the forecast errors at the 12-month horizon in both datasets have higher standard deviation than the forecast errors at the 3-month horizon Exceptions are Australia, Canada, Denmark, Euro Area, New Zealand, Norway, Sweden, Switzerland, Chile, Colombia, Indonesia, Peru, Singapore, and Thailand at the 24-month horizon. All exceptions come from Consensus Economics survey.
} 
Table 1

Summary statistics of actual depreciation: $s_{t+h}-s_{t}$.

\begin{tabular}{|c|c|c|c|c|c|c|c|c|c|c|}
\hline \multicolumn{5}{|c|}{ Forecast horizon $h=3$} & \multicolumn{4}{|l|}{$h=12$} & \multirow{2}{*}{\multicolumn{2}{|c|}{$\begin{array}{l}h=24 \\
\text { Consensus }\end{array}$}} \\
\hline \multirow[b]{2}{*}{ Country } & \multicolumn{2}{|c|}{ Consensus } & \multicolumn{2}{|c|}{ FX4Casts } & \multicolumn{2}{|c|}{ Consensus } & \multicolumn{2}{|c|}{ FX4Casts } & & \\
\hline & Mean & SD & Mean & SD & Mean & SD & Mean & SD & Mean & SD \\
\hline \multicolumn{11}{|c|}{ A. Developed countries } \\
\hline Australia & 0.85 & 7.37 & 0.84 & 7.47 & 4.20 & 13.76 & 4.20 & 14.04 & 9.01 & 14.50 \\
\hline Canada & -0.80 & 4.62 & -0.80 & 4.96 & -3.25 & 9.26 & -3.24 & 9.70 & -6.55 & 9.11 \\
\hline Denmark & -0.05 & 5.25 & -0.12 & 5.18 & -0.34 & 9.39 & -0.44 & 9.26 & -1.83 & 10.35 \\
\hline Euro Area & -0.06 & 5.28 & -0.12 & 5.21 & -0.34 & 9.40 & -0.44 & 9.39 & -1.84 & 10.38 \\
\hline Japan & -0.85 & 4.78 & -0.73 & 4.88 & -3.88 & 7.74 & -3.71 & 7.84 & -9.03 & 12.05 \\
\hline New Zealand & 0.53 & 7.18 & 0.54 & 7.22 & 2.40 & 14.64 & 2.46 & 14.78 & 4.28 & 14.96 \\
\hline Norway & -0.52 & 6.30 & -0.56 & 6.54 & -1.77 & 12.04 & -1.85 & 11.90 & -3.88 & 11.51 \\
\hline Sweden & -0.22 & 6.49 & -0.29 & 6.74 & -0.92 & 12.37 & -1.02 & 12.54 & -2.88 & 13.60 \\
\hline Switzerland & -0.81 & 5.51 & -0.84 & 5.33 & -3.45 & 9.79 & -3.52 & 9.66 & -8.68 & 9.45 \\
\hline U.K. & 0.42 & 5.03 & -0.43 & 5.37 & 1.89 & 10.38 & -1.84 & 10.82 & 4.04 & 13.65 \\
\hline \multicolumn{11}{|c|}{ B. Developing countries } \\
\hline Argentina & 1.41 & 2.48 & 1.43 & 2.60 & 5.45 & 5.72 & 5.47 & 5.87 & 11.14 & 7.19 \\
\hline Bangladesh & 0.93 & 1.96 & 0.93 & 2.12 & 4.05 & 4.43 & 4.08 & 4.35 & 6.65 & 6.58 \\
\hline Bolivia & -0.36 & 0.98 & -0.33 & 1.19 & -1.71 & 3.12 & -1.58 & 3.25 & -4.11 & 4.70 \\
\hline Brazil & -0.97 & 8.18 & -0.99 & 8.40 & -5.07 & 16.04 & -5.00 & 16.49 & -11.08 & 17.20 \\
\hline Chile & -0.61 & 6.37 & -0.54 & 6.60 & -2.91 & 11.00 & -2.75 & 11.24 & -5.43 & 11.33 \\
\hline Colombia & -1.19 & 6.81 & -1.13 & 6.75 & -4.84 & 11.20 & -4.61 & 11.74 & -8.82 & 10.88 \\
\hline Egypt & -0.03 & 1.79 & -0.03 & 1.69 & -0.31 & 4.10 & -0.28 & 4.02 & 0.00 & 5.84 \\
\hline India & 0.50 & 4.49 & 0.52 & 4.53 & 2.10 & 10.20 & 2.08 & 10.47 & 3.16 & 10.70 \\
\hline Indonesia & 0.38 & 4.97 & 0.38 & 5.52 & 0.68 & 9.70 & 0.60 & 10.43 & -0.64 & 11.11 \\
\hline Israel & -0.47 & 4.21 & -0.43 & 4.46 & -1.83 & 8.74 & -1.89 & 9.00 & -5.29 & 9.66 \\
\hline Mexico & 0.42 & 5.84 & 0.43 & 5.79 & 1.85 & 10.11 & 1.88 & 10.32 & 4.00 & 11.31 \\
\hline Nigeria & 0.40 & 3.93 & 0.43 & 4.02 & 2.12 & 8.88 & 2.19 & 9.11 & 4.76 & 11.44 \\
\hline Pakistan & 1.48 & 2.54 & 1.48 & 2.68 & 5.88 & 7.13 & 5.88 & 7.25 & 11.98 & 10.51 \\
\hline Paraguay & -0.94 & 5.74 & -0.91 & 5.89 & -3.79 & 11.18 & -3.72 & 11.46 & -9.85 & 12.50 \\
\hline Peru & -0.85 & 2.51 & -0.84 & 2.55 & -3.28 & 4.97 & -3.24 & 4.97 & -6.32 & 4.41 \\
\hline Philippines & -0.87 & 3.23 & -0.89 & 3.22 & -3.53 & 6.99 & -3.56 & 7.15 & -7.45 & 8.80 \\
\hline Singapore & -0.93 & 2.72 & -0.94 & 2.76 & -3.74 & 5.11 & -3.79 & 5.15 & -8.24 & 5.28 \\
\hline South Africa & 0.71 & 8.37 & -0.71 & 7.97 & 3.03 & 14.67 & 3.09 & 14.29 & 5.25 & 17.45 \\
\hline South Korea & -0.20 & 6.32 & -0.24 & 6.02 & -0.18 & 14.13 & -0.20 & 14.21 & 0.88 & 18.63 \\
\hline Taiwan & -0.39 & 2.77 & -0.39 & 2.92 & -1.50 & 5.01 & -1.52 & 5.07 & -2.98 & 5.44 \\
\hline Thailand & -0.69 & 3.24 & -0.70 & 3.79 & -3.20 & 5.92 & -3.24 & 8.17 & -7.58 & 7.26 \\
\hline Uruguay & -0.96 & 5.96 & -1.18 & 5.48 & -4.21 & 10.90 & -4.31 & 10.82 & -8.29 & 8.95 \\
\hline Vietnam & 0.81 & 1.64 & 0.81 & 1.62 & 3.54 & 3.57 & 3.53 & 3.57 & 7.83 & 5.83 \\
\hline
\end{tabular}

Notes: The table reports the mean (Mean) and standard deviation (SD) of the actual exchange rate depreciation for 3-, 12-, and 24-month ahead exchange rate forecasts of the foreign currency relative to the U.S. dollar. The column "Consensus" shows the summary statistics for Consensus Economics dataset, and the column "FX4Casts" contain the statistics for FX4Casts dataset. The sample covers the period from January 2004 to December 2012.

ation is mixed. Frankel and Froot (1987), Dominguez (1986), and Cavaglia et al. (1993) report the same finding for the standard deviation, while they find smaller absolute mean in expected exchange rate changes.

To illustrate the differences in expectations between Consensus Economics and FX4Casts, we plot 3- and 12-month forecast errors for four developed countries (the Euro Area, Japan, the U.K., and Australia) and four developing countries (Mexico, Singapore, South Korea, and South Africa) in Figs. 1 and 2. We have selected four countries from each group based on the highest foreign exchange market turnover in the 2013 Bank for International Settlements (BIS) Triennial Central Bank Survey. For 3month ahead forecasts, the forecast errors from the two datasets do not differ substantially. At the 12-month horizon, the discrepancies between the two sources of forecasts are more pronounced, with larger forecast errors generally observed for FX4Casts. ${ }^{13}$

\section{Rationality of survey-based expectations}

Since Muth's (1961) seminal paper, many definitions and tests of rationality have been proposed. Two conventional tests of the rationality of survey-based expectations include testing for the unbiasedness and orthogonality of forecasts. The tests of unbiasedness involve testing whether the expected exchange rate is an unbiased predictor of the future spot rate. The orthogonality condition assumes that professional forecasters fully incorporate all the available information at the time

\footnotetext{
13 We do not plot 24-month forecast errors from Consensus Economics, as they cannot be compared to their counterpart from FX4Casts. Although FX4Casts started collecting 24-month exchange rate forecasts in January 2008, we do not study them in this paper to prevent restricting the sample to only four years of data, two of which are dominated by the financial crisis of 2008-2009.
} 
Table 2

Summary statistics of expected depreciation: $s_{t+h, t}^{e}-s_{t}$.

\begin{tabular}{|c|c|c|c|c|c|c|c|c|c|c|}
\hline \multicolumn{5}{|c|}{ Forecast Horizon $h=3$} & \multicolumn{4}{|l|}{$h=12$} & \multirow{2}{*}{\multicolumn{2}{|c|}{$\begin{array}{l}h=24 \\
\text { Consensus }\end{array}$}} \\
\hline \multirow[b]{2}{*}{ Country } & \multicolumn{2}{|c|}{ Consensus } & \multicolumn{2}{|c|}{ FX4Casts } & \multicolumn{2}{|c|}{ Consensus } & \multicolumn{2}{|c|}{ FX4Casts } & & \\
\hline & Mean & SD & Mean & SD & Mean & SD & Mean & SD & Mean & SD \\
\hline \multicolumn{11}{|c|}{ A. Developed countries } \\
\hline Australia & -1.05 & 2.77 & -0.12 & 1.77 & -2.73 & 3.38 & -0.12 & 4.29 & -4.48 & 5.46 \\
\hline Canada & 0.39 & 1.72 & -0.20 & 1.16 & 0.87 & 2.37 & -0.43 & 2.65 & 1.12 & 3.14 \\
\hline Denmark & 0.23 & 1.93 & 0.10 & 1.65 & 0.54 & 3.41 & 0.02 & 3.86 & 1.61 & 4.70 \\
\hline Euro Area & 0.22 & 1.93 & -0.02 & 1.63 & 0.52 & 3.40 & 0.05 & 3.91 & 1.61 & 4.69 \\
\hline Japan & -0.65 & 2.81 & -0.04 & 1.80 & -0.62 & 6.66 & -0.24 & 4.93 & -2.13 & 8.39 \\
\hline New Zealand & -1.92 & 2.77 & -0.01 & 1.97 & -5.02 & 3.96 & -0.25 & 4.21 & -8.07 & 6.15 \\
\hline Norway & -0.94 & 2.26 & -0.55 & 1.21 & -2.31 & 3.66 & -2.15 & 3.05 & -0.96 & 5.16 \\
\hline Sweden & -1.01 & 2.47 & -0.55 & 1.69 & -2.97 & 3.88 & -2.21 & 3.36 & -3.65 & 5.95 \\
\hline Switzerland & 0.03 & 2.48 & -0.05 & 1.74 & 0.33 & 4.72 & 0.13 & 4.12 & -0.10 & 5.46 \\
\hline U.K. & 0.62 & 1.66 & -0.11 & 1.46 & 0.56 & 2.78 & -0.15 & 3.43 & 1.25 & 4.28 \\
\hline \multicolumn{11}{|c|}{ B. Developing countries } \\
\hline Argentina & 1.74 & 1.52 & 0.86 & 1.08 & 6.57 & 4.92 & 4.27 & 3.76 & 11.64 & 8.40 \\
\hline Bangladesh & 1.59 & 1.22 & 0.91 & 1.05 & 4.39 & 1.87 & 3.07 & 2.28 & 7.06 & 2.57 \\
\hline Bolivia & 0.77 & 0.57 & -0.03 & 0.43 & 2.43 & 1.96 & 0.01 & 2.01 & 5.76 & 3.56 \\
\hline Brazil & 0.36 & 2.87 & -0.08 & 1.85 & 4.19 & 4.26 & 0.37 & 4.12 & 9.08 & 5.00 \\
\hline Chile & 0.42 & 1.72 & -0.10 & 1.24 & 2.42 & 2.25 & -1.22 & 2.73 & 4.91 & 3.04 \\
\hline Colombia & 1.20 & 2.91 & -0.37 & 1.34 & 4.26 & 4.22 & -1.46 & 2.82 & 8.30 & 4.62 \\
\hline Egypt & 0.92 & 1.30 & 0.46 & 0.84 & 2.62 & 2.19 & 0.88 & 2.77 & 4.81 & 2.70 \\
\hline India & -0.59 & 1.56 & -0.48 & 0.97 & -1.86 & 2.42 & -2.89 & 1.50 & -0.71 & 3.59 \\
\hline Indonesia & -0.19 & 2.00 & -0.58 & 0.97 & -1.30 & 2.54 & -2.29 & 1.59 & -1.80 & 3.88 \\
\hline Israel & 0.53 & 1.99 & 0.07 & 0.77 & 0.98 & 2.98 & 0.81 & 2.96 & 2.48 & 3.45 \\
\hline Mexico & 0.18 & 2.40 & 0.04 & 1.34 & 1.96 & 3.31 & 0.40 & 2.74 & 4.79 & 3.30 \\
\hline Nigeria & 1.45 & 2.89 & 0.67 & 1.04 & 4.76 & 3.66 & 2.16 & 3.43 & 11.05 & 7.62 \\
\hline Pakistan & 1.74 & 1.25 & 0.87 & 0.85 & 4.84 & 2.10 & 2.96 & 2.62 & 8.14 & 2.69 \\
\hline Paraguay & 2.89 & 3.06 & -0.34 & 0.94 & 6.82 & 3.93 & -1.19 & 3.23 & 11.37 & 4.62 \\
\hline Peru & -0.07 & 1.41 & -0.45 & 0.82 & 0.36 & 1.78 & -1.06 & 2.36 & 1.65 & 2.18 \\
\hline Philippines & 0.32 & 1.60 & -0.32 & 0.92 & -0.52 & 2.61 & -1.54 & 2.66 & 0.86 & 3.07 \\
\hline Singapore & -0.55 & 1.44 & -0.53 & 0.75 & -2.40 & 1.77 & -2.46 & 1.33 & -3.76 & 1.54 \\
\hline South Africa & 1.52 & 3.79 & 0.47 & 2.09 & 4.91 & 5.76 & 3.46 & 2.63 & 8.64 & 8.24 \\
\hline South Korea & -1.26 & 1.88 & -0.58 & 1.09 & -4.46 & 3.89 & -3.12 & 1.75 & -5.68 & 6.14 \\
\hline Taiwan & -0.86 & 1.21 & -0.59 & 0.68 & -2.93 & 1.47 & -2.78 & 1.44 & -4.83 & 1.74 \\
\hline Thailand & -0.39 & 1.74 & -0.10 & 1.28 & -1.56 & 2.30 & -0.99 & 2.69 & -1.91 & 2.37 \\
\hline Uruguay & 1.84 & 3.13 & -0.34 & 1.07 & 5.29 & 3.34 & -0.74 & 3.53 & 9.18 & 4.12 \\
\hline Vietnam & 0.88 & 0.82 & 0.46 & 0.51 & 2.34 & 1.35 & 2.06 & 1.25 & 3.02 & 1.67 \\
\hline
\end{tabular}

Notes: The table reports the mean (Mean) and standard deviation (SD) of the expected exchange rate depreciation for 3-, 12-, and 24-month ahead exchange rate forecasts of the foreign currency relative to the U.S. dollar. The column "Consensus" shows the summary statistics for Consensus Economics dataset, and the column "FX4Casts" contain the summary statistics for FX4Casts dataset. The sample covers the period from January 2004 to December 2012.

when the forecasts are formed. Thus, the forecast error should be orthogonal to the variables in the information set of the forecasters.

\subsection{Unbiasedness of expectations}

The unbiasedness of exchange rate expectations can be tested by regressing the actual exchange rate change on the expected change,

$$
s_{t+h}-s_{t}=\alpha+\beta\left(s_{t+h, t}^{e}-s_{t}\right)+u_{t+h}
$$

where $s_{t}$ is the log of the U.S. dollar nominal exchange rate determined as the foreign price of unit of domestic currency, so that an increase in $s_{t}$ is an appreciation of the dollar, $s_{t+h, t}^{e}$ is the survey-based expectation made at period $t$ of the spot exchange rate at period $t+h$, and $u_{t+h}$ is the white noise error term. Testing for the unbiasedness of exchange rate expectations involves testing a joint null hypothesis that $\alpha=0$ and $\beta=1$ in Eq. (1). We estimate Eq. (1) using OLS for $h=3$, 12, and 24 months with Consensus Economics data, and for $h=3$ and 12 months with FX4Casts data.

However, a rejection of the unbiasedness hypothesis does not necessarily imply that the exchange rate expectations are formed irrationally. As previous studies have shown, biased expectations can still be rational in the presence of the peso problem, adaptive learning, or heterogeneous expectations. Therefore, the finding that the expected exchange rate depreciation is a biased estimate of the actual depreciation does not constitute direct evidence of irrationality. From the point of view of statistical inference, Bonham and Cohen (2001) demonstrate that when micro-homogeneity of expectations does not hold, the use of consensus forecasts may lead to false acceptance of the unbiasedness hypothesis. Unfortunately, we cannot test exchange rate forecasts for heterogeneity, because individual forecasts are not available in both datasets. Since the 
Table 3

Summary statistics of forecast errors: $s_{t+h}-s_{t+h, t}^{e}$.

\begin{tabular}{|c|c|c|c|c|c|c|c|c|c|c|}
\hline \multicolumn{5}{|c|}{ Forecast horizon $h=3$} & \multicolumn{4}{|l|}{$h=12$} & \multirow{2}{*}{\multicolumn{2}{|c|}{$\begin{array}{l}h=24 \\
\text { Consensus }\end{array}$}} \\
\hline \multirow[b]{2}{*}{ Country } & \multicolumn{2}{|c|}{ Consensus } & \multicolumn{2}{|c|}{ FX4Casts } & \multicolumn{2}{|c|}{ Consensus } & \multicolumn{2}{|c|}{ FX4Casts } & & \\
\hline & Mean & SD & Mean & SD & Mean & SD & Mean & SD & Mean & SD \\
\hline \multicolumn{11}{|c|}{ A. Developed countries } \\
\hline Australia & 1.90 & 8.16 & 0.92 & 7.61 & 6.92 & 12.47 & 4.01 & 13.88 & 13.49 & 11.16 \\
\hline Canada & -1.20 & 4.98 & -0.62 & 5.13 & -4.12 & 7.97 & -2.98 & 8.83 & -7.67 & 7.42 \\
\hline Denmark & -0.29 & 5.49 & -0.20 & 5.44 & -0.88 & 8.28 & -0.38 & 8.96 & -3.44 & 6.84 \\
\hline Euro Area & -0.28 & 5.53 & 0.11 & 5.38 & -0.86 & 8.29 & 0.30 & 9.05 & -3.44 & 6.88 \\
\hline Japan & -0.20 & 5.68 & -0.66 & 5.36 & -3.26 & 11.44 & -3.09 & 10.50 & -6.90 & 15.26 \\
\hline New Zealand & 2.45 & 7.85 & 0.51 & 7.54 & 7.42 & 13.40 & 2.41 & 14.85 & 12.35 & 10.46 \\
\hline Norway & 0.42 & 6.71 & 0.00 & 6.63 & 0.54 & 9.87 & 0.21 & 11.16 & -2.92 & 8.65 \\
\hline Sweden & 0.79 & 6.98 & 0.27 & 6.95 & 2.05 & 10.38 & 1.09 & 11.72 & 0.77 & 9.38 \\
\hline Switzerland & -0.84 & 5.93 & -0.77 & 5.62 & -3.78 & 9.74 & -3.57 & 10.45 & -8.57 & 9.70 \\
\hline U.K. & -0.20 & 5.24 & -0.34 & 5.51 & 1.33 & 8.81 & -1.70 & 9.60 & 2.80 & 11.13 \\
\hline \multicolumn{11}{|c|}{ B. Developing countries } \\
\hline Argentina & -0.33 & 2.23 & 0.64 & 2.64 & -1.12 & 6.11 & 2.11 & 6.30 & -0.50 & 9.51 \\
\hline Bangladesh & -0.66 & 2.59 & 0.04 & 2.17 & -0.35 & 5.41 & 1.34 & 4.66 & -0.41 & 6.48 \\
\hline Bolivia & -1.13 & 1.14 & -0.31 & 1.14 & -4.15 & 3.26 & -1.80 & 2.84 & -9.87 & 5.44 \\
\hline Brazil & -1.33 & 8.99 & -0.94 & 8.64 & -9.26 & 16.58 & -5.83 & 18.06 & -20.16 & 18.75 \\
\hline Chile & -1.03 & 6.36 & -0.42 & 6.44 & -5.33 & 10.02 & -1.41 & 11.31 & -10.33 & 9.77 \\
\hline Colombia & -2.39 & 7.49 & -0.74 & 6.87 & -9.10 & 10.89 & -3.02 & 12.58 & -17.12 & 10.29 \\
\hline Egypt & -0.94 & 2.25 & -0.45 & 1.70 & -2.94 & 4.66 & -0.92 & 4.92 & -4.81 & 6.40 \\
\hline India & 1.09 & 4.77 & 1.00 & 4.60 & 3.95 & 10.70 & 4.99 & 10.60 & 3.87 & 11.54 \\
\hline Indonesia & 0.57 & 5.62 & 0.97 & 5.70 & 1.97 & 9.26 & 2.83 & 10.70 & 1.17 & 8.80 \\
\hline Israel & -0.92 & 4.67 & -0.47 & 4.63 & -2.81 & 8.48 & -2.23 & 10.31 & -7.77 & 8.98 \\
\hline Mexico & 0.25 & 6.26 & 0.38 & 6.11 & -0.11 & 9.93 & 1.09 & 10.32 & -0.79 & 11.14 \\
\hline Nigeria & -1.05 & 5.12 & -0.22 & 4.13 & -2.64 & 10.22 & 0.16 & 10.43 & -6.29 & 15.45 \\
\hline Pakistan & -0.27 & 2.86 & 0.67 & 2.78 & 1.04 & 7.63 & 3.28 & 7.35 & 3.84 & 10.87 \\
\hline Paraguay & -3.83 & 6.09 & -0.55 & 5.93 & -10.61 & 10.12 & -2.32 & 12.49 & -21.22 & 11.42 \\
\hline Peru & -0.78 & 3.26 & -0.42 & 2.67 & -3.64 & 5.97 & -2.44 & 5.99 & -7.96 & 5.50 \\
\hline Philippines & -1.19 & 3.56 & -0.58 & 3.26 & -3.01 & 8.06 & -1.65 & 7.68 & -8.31 & 9.72 \\
\hline Singapore & -0.37 & 3.17 & -0.41 & 3.01 & -1.33 & 5.65 & -2.17 & 7.77 & -4.48 & 5.61 \\
\hline South Africa & -0.80 & 9.21 & 0.25 & 8.14 & -1.87 & 14.26 & -0.51 & 14.11 & -3.39 & 15.15 \\
\hline South Korea & 1.06 & 6.13 & 0.34 & 6.12 & 4.28 & 12.99 & 2.92 & 14.35 & 6.56 & 16.53 \\
\hline Taiwan & 0.47 & 3.14 & 0.21 & 3.12 & 1.43 & 4.85 & 1.35 & 5.44 & 1.85 & 5.32 \\
\hline Thailand & -0.31 & 3.78 & -0.61 & 4.29 & -1.64 & 7.02 & -2.44 & 8.18 & -5.67 & 7.09 \\
\hline Uruguay & -2.80 & 6.72 & -0.86 & 5.79 & -9.50 & 11.32 & -3.58 & 13.17 & -17.48 & 10.02 \\
\hline Vietnam & -0.07 & 1.75 & 0.35 & 1.62 & 1.20 & 3.94 & 1.25 & 3.58 & 4.81 & 7.06 \\
\hline
\end{tabular}

Notes: The table reports the mean (Mean) and standard deviation (SD) of the forecast errors for 3-, 12-, and 24-month ahead exchange rate forecasts of the foreign currency relative to the U.S. dollar. The column "Consensus" shows the summary statistics for Consensus Economics dataset, and the column

"FX4Casts" contain the summary statistics for FX4Casts dataset. The sample covers the period from January 2004 to December 2012.

previous studies, such as Frankel and Froot (1987), Ito (1990), Takagi (1991), Elliott and Ito (1999), Bénassy-Quéré et al. (2003), and Dreger and Stadtmann (2008) present overwhelming evidence of heterogeneity in exchange rate expectations, we further examine the rationality of forecasts with orthogonality tests.

Table 4 reports the results of estimating Eq. (1) for 3-, 12-, and 24-month ahead forecasts from both datasets. Since the overlapping nature of the exchange rate expectations leads to serial correlation of order $h-1$ in the error terms of Eq. (1), the statistical significance of the estimated coefficients is determined based on the Newey-West standard errors. For each forecast horizon, we report the $p$-values for the joint null that $\alpha=0$ and $\beta=1$. At the 3-month horizon, we find strong evidence against the unbiasedness hypothesis with both datasets. Using Consensus Economics data, the joint null hypothesis of unbiasedness is rejected for all 10 developed countries, and for 19 out of 23 developing countries at least at the 10 percent significance level. Similarly, the joint null of unbiasedness is rejected for 9 out of 10 developed countries, and for 18 out of 24 developing countries in FX4Casts dataset.

As the forecast horizon increases to 12 months, the bias in the forecasts for developed countries' currencies decreases drastically. This finding is consistent with the results in Cavaglia et al. (1993) for 10 developed countries' currencies visà-vis the U.S. dollar from 1986 to 1990 at the 3-, 6-, and 12-month horizon. At the 12-month horizon, the joint null hypothesis of unbiasedness is rejected for 5 out of 10 developed countries (Australia, Canada, Japan, New Zealand, and Switzerland) in Consensus Economics data, and for 3 out of 10 developed countries (Canada, Japan, and Switzerland) in FX4Casts data.

However, the bias in the forecasts for developing countries does not decrease with the forecast horizon. At the 12-month horizon, the joint null of unbiasedness is still rejected for 17 out of 23 developing countries in Consensus Economics data, and for 15 out of 23 developing countries in FX4Casts data. As we expand the forecast horizon to 24 months, the joint null 


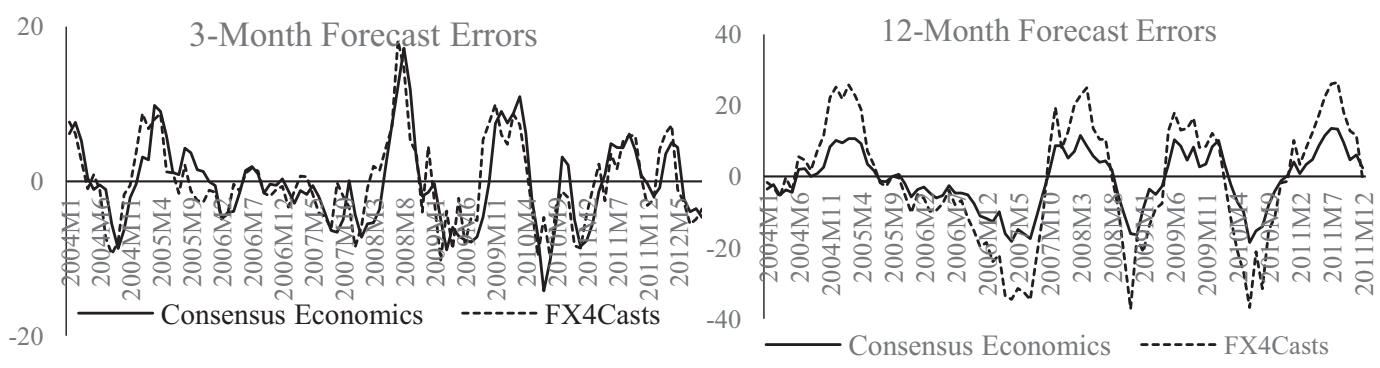

A. Euro Area

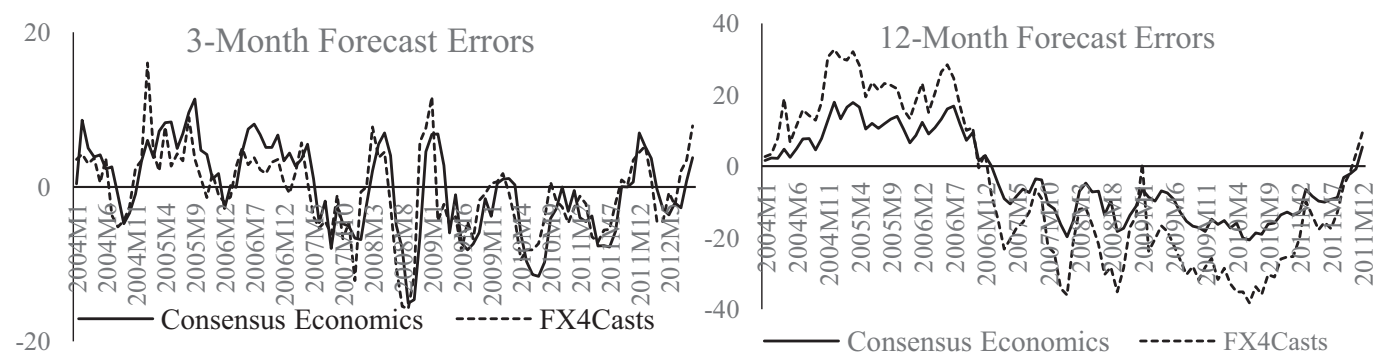

B. Japan

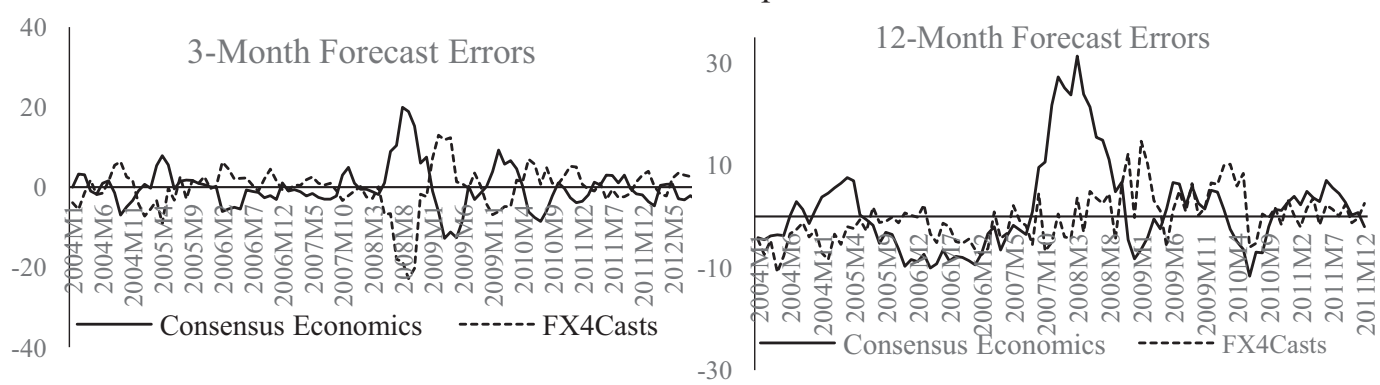

C. The United Kingdom

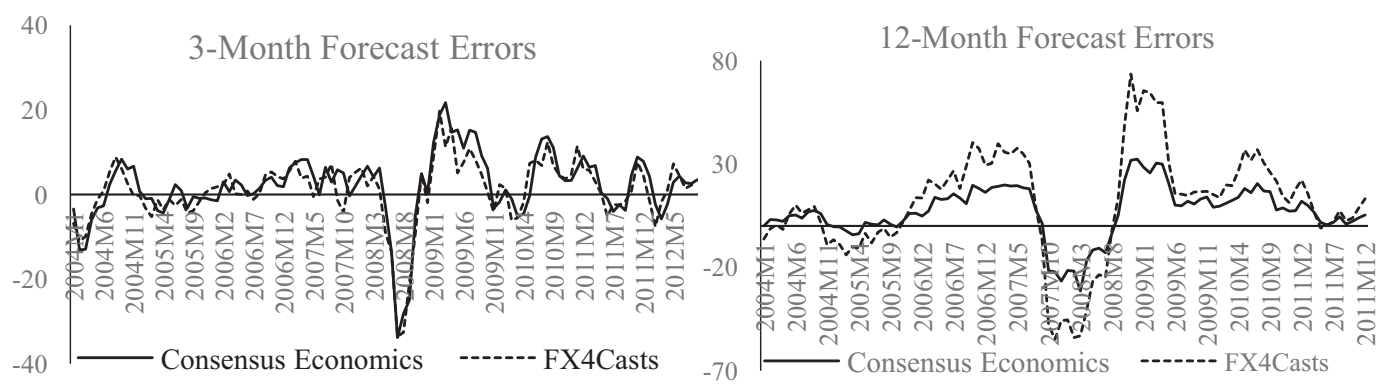

D. Australia

Fig. 1. Forecast errors for selected developed countries.

hypothesis of unbiasedness is again rejected for all developed countries, except the U.K., and for 18 out of 23 developing countries Consensus Economics data.

Overall, the evidence of forecast rationality is stronger at the 12-month forecast horizon than at the 3-and 24-month horizon. Forecasts for both developed and developing countries are biased for the majority of countries at the 3-month horizon. As the forecast horizon increases to 12 months, the bias in the exchange rate forecasts sharply decreases for developed countries, but does not decline significantly for developing countries. This improvement in the unbiasedness of the forecasts for developed countries disappears at the 24-month horizon. 


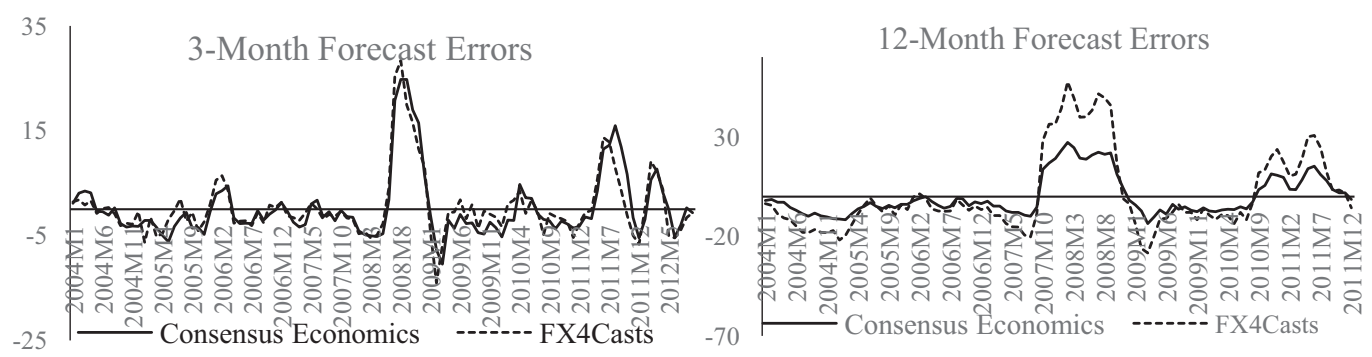

A. Mexico
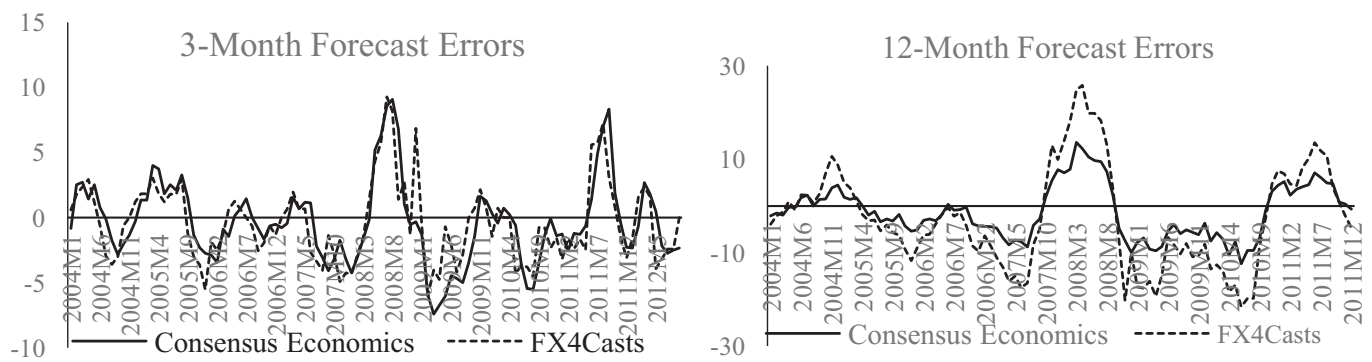

B. Singapore
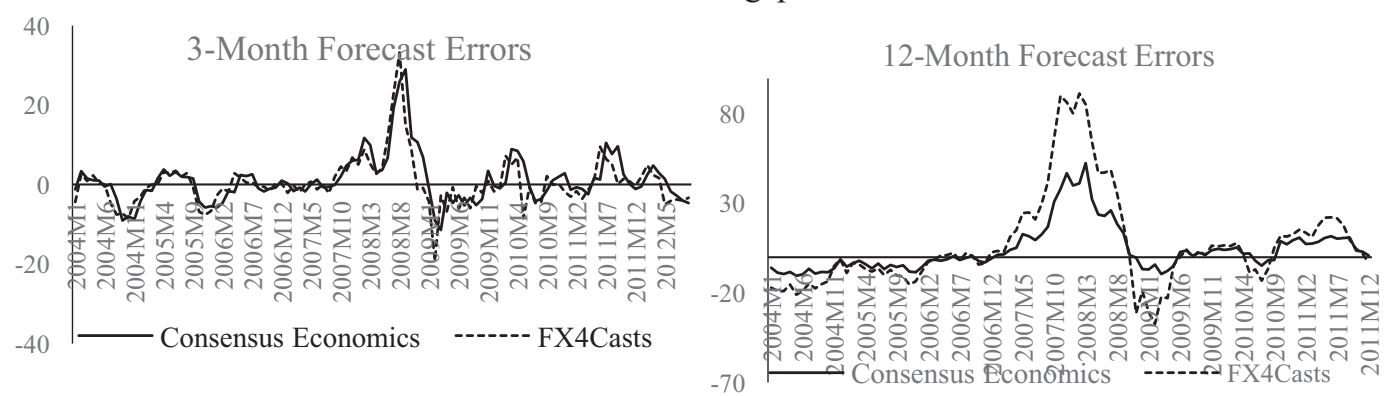

C. South Korea
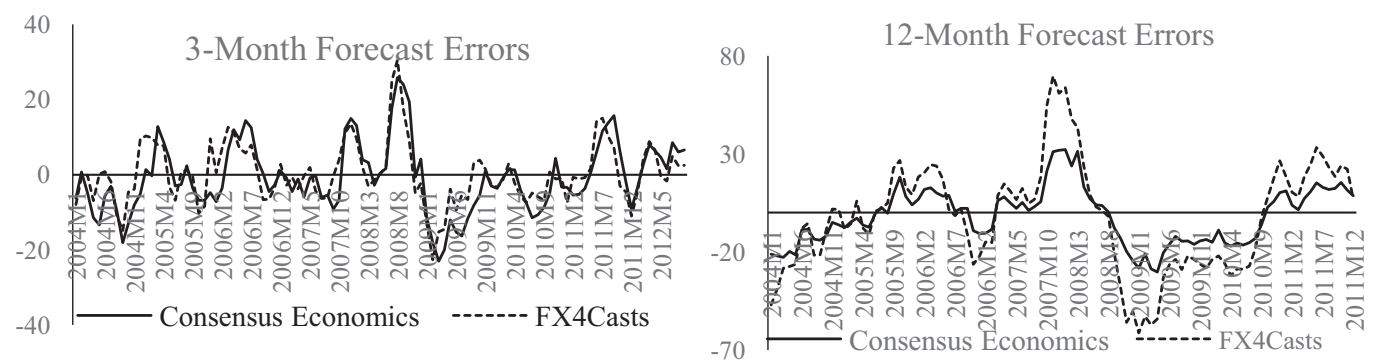

D. South Africa

Fig. 2. Forecast errors for selected developing countries.

\subsection{Orthogonality of expectations}

The second test of the rationality of exchange rate expectations is concerned with the efficient use of information available to market participants at the time they form their forecasts. If professional forecasters fully incorporate the information that is available to them at the time they make their predictions, any variable that belongs to their information set should be orthogonal to the forecast error. 
Table 4

Tests of unbiasedness: $s_{t+h}-s_{t}=\alpha+\beta\left(s_{t+h}^{e}-s_{t}\right)+u_{t+h}$.

\begin{tabular}{|c|c|c|c|c|c|c|c|c|c|c|}
\hline \multicolumn{5}{|c|}{ Forecast horizon $h=3$} & \multicolumn{4}{|l|}{$h=12$} & \multirow{2}{*}{\multicolumn{2}{|c|}{$\begin{array}{l}h=24 \\
\text { Consensus }\end{array}$}} \\
\hline \multirow[b]{2}{*}{ Country } & \multicolumn{2}{|c|}{ Consensus } & \multicolumn{2}{|l|}{ FX4Casts } & \multicolumn{2}{|c|}{ Consensus } & \multicolumn{2}{|l|}{ FX4Casts } & & \\
\hline & $\hat{\beta}$ & F-stat & $\hat{\beta}$ & F-stat & $\hat{\beta}$ & F-stat & $\hat{\beta}$ & F-stat & $\hat{\beta}$ & F-stat \\
\hline \multicolumn{11}{|c|}{ A. Developed countries } \\
\hline Australia & -0.29 & $0.000^{* * * *}$ & 0.16 & $0.036^{* *}$ & $1.99^{* * * *}$ & $0.005^{* * * *}$ & 0.61 & 0.469 & $1.94^{* * *}$ & $0.000^{* * * *}$ \\
\hline Canada & -0.08 & $0.000^{* * *}$ & -0.11 & $0.001^{* * * *}$ & $2.48^{* * *}$ & $0.000^{* * *}$ & $1.61^{*}$ & $0.000^{* * * *}$ & $1.92^{* * *}$ & $0.000^{* * *}$ \\
\hline Denmark & 0.15 & $0.029^{* *}$ & -0.00 & $0.000^{* * *}$ & $1.35^{* * *}$ & 0.546 & $0.67^{*}$ & 0.665 & $1.87^{* * *}$ & $0.000^{* * *}$ \\
\hline Euro Area & 0.14 & $0.026^{* *}$ & 0.17 & $0.019^{* *}$ & $1.36^{* * * *}$ & 0.525 & $0.69^{*}$ & 0.713 & $1.87^{* * *}$ & $0.000^{* * *}$ \\
\hline Japan & -0.10 & $0.000^{* * *}$ & -0.25 & $0.002^{* * *}$ & -0.30 & $0.000^{* * *}$ & -0.44 & $0.000^{* * * *}$ & -0.12 & $0.000^{* * * *}$ \\
\hline New Zealand & -0.15 & $0.000^{* * * *}$ & -0.09 & $0.013^{* *}$ & $1.61^{*}$ & $0.002^{* * * *}$ & 0.44 & 0.727 & $2.01^{* * *}$ & $0.000^{* * *}$ \\
\hline Norway & -0.03 & $0.006^{* * *}$ & 0.09 & 0.140 & $2.27^{* * *}$ & $0.075^{*}$ & 1.34 & 0.912 & $1.58^{* * *}$ & $0.001^{* * *}$ \\
\hline Sweden & -0.04 & $0.003^{* * *}$ & 0.02 & $0.001^{* * *}$ & $2.00^{* * * *}$ & 0.278 & 1.31 & 0.897 & $1.87^{* * *}$ & $0.000^{* * * *}$ \\
\hline Switzerland & 0.11 & $0.030^{* * *}$ & -0.03 & $0.003^{* * *}$ & 0.52 & 0.223 & 0.07 & $0.076^{*}$ & $0.43^{*}$ & $0.006^{* * *}$ \\
\hline U.K. & 0.11 & $0.029^{* *}$ & 0.14 & $0.072^{*}$ & $2.45^{* * *}$ & 0.171 & $1.46^{*}$ & 0.730 & $2.20^{* * *}$ & 0.117 \\
\hline \multicolumn{11}{|c|}{ B. Developing countries } \\
\hline Argentina & $0.76^{* * *}$ & 0.263 & 0.39 & 0.179 & $0.41^{* * *}$ & $0.004^{* * * *}$ & 0.14 & 0.352 & 0.23 & $0.000^{* * * *}$ \\
\hline Bangladesh & $-0.47^{* * *}$ & $0.000^{* * *}$ & 0.41 & $0.089^{*}$ & $-0.88^{*}$ & $0.002^{* * * *}$ & 0.20 & $0.037^{* *}$ & 0.60 & 0.771 \\
\hline Bolivia & 0.01 & $0.000^{* * *}$ & $0.84^{* *}$ & $0.001^{* * *}$ & $0.39^{*}$ & $0.000^{* * *}$ & $0.80^{* * * *}$ & $0.000^{* * *}$ & 0.21 & $0.000^{* * * *}$ \\
\hline Brazil & -0.35 & $0.000^{* * *}$ & 0.08 & $0.004^{* * *}$ & 0.02 & $0.032^{* * *}$ & -1.11 & $0.001^{* * * *}$ & -0.62 & $0.000^{* * * *}$ \\
\hline Chile & 0.52 & 0.138 & $1.13^{* *}$ & 0.769 & $2.52^{* * *}$ & $0.000^{* * *}$ & 0.39 & 0.670 & $2.28^{* * *}$ & $0.000^{* * * *}$ \\
\hline Colombia & -0.07 & $0.000^{* * *}$ & 0.05 & 0.190 & 0.69 & $0.003^{* * *}$ & -0.77 & $0.002^{* * *}$ & 0.79 & $0.000^{* * *}$ \\
\hline Egypt & -0.04 & $0.000^{* * * *}$ & $0.47^{* * *}$ & $0.004^{* * * *}$ & -0.01 & $0.000^{* * * *}$ & -0.01 & $0.022^{* *}$ & 0.03 & $0.000^{* * * *}$ \\
\hline India & -0.03 & $0.020^{* *}$ & 0.17 & $0.021^{* *}$ & -0.39 & $0.037^{* *}$ & -0.05 & 0.101 & -0.22 & $0.054^{*}$ \\
\hline Indonesia & -0.37 & $0.000^{* * *}$ & -0.52 & $0.000^{* * * *}$ & $1.15^{*}$ & 0.703 & -0.52 & $0.076^{*}$ & $2.03^{* * * *}$ & $0.018^{* * *}$ \\
\hline Israel & -0.02 & $0.000^{* * * *}$ & -0.85 & $0.009^{* * *}$ & 0.75 & 0.450 & $-1.15^{* *}$ & $0.000^{* * * *}$ & $1.03^{* *}$ & $0.036^{* *}$ \\
\hline Mexico & 0.06 & $0.048^{* *}$ & $-0.52^{*}$ & $0.000^{* * * *}$ & $0.67^{* * *}$ & 0.483 & 0.51 & 0.513 & 0.68 & 0.917 \\
\hline Nigeria & -0.15 & $0.000^{\text {**** }}$ & 0.09 & $0.014^{* *}$ & $-0.46^{* *}$ & $0.000^{* * *}$ & -0.49 & $0.000^{* * * *}$ & $-0.43^{* * *}$ & $0.000^{* * * *}$ \\
\hline Pakistan & -0.05 & $0.006^{* * *}$ & 0.06 & $0.006^{* * *}$ & -0.33 & $0.001^{* * *}$ & 0.38 & $0.039^{* *}$ & -0.03 & $0.001^{* * * *}$ \\
\hline Paraguay & 0.28 & $0.000^{* * * *}$ & 0.19 & 0.193 & $1.23^{* *}$ & $0.000^{* * * *}$ & -0.75 & $0.000^{* * * *}$ & $1.10^{* *}$ & $0.000^{* * * *}$ \\
\hline Peru & $-0.60^{* *}$ & $0.000^{* * * *}$ & 0.03 & $0.007^{* * *}$ & $-1.21^{* * *}$ & $0.000^{* * *}$ & $-0.49^{* *}$ & $0.000^{* * * *}$ & $-0.64^{* *}$ & $0.000^{* * *}$ \\
\hline Philippines & 0.07 & $0.000^{* * * *}$ & 0.32 & 0.132 & $-0.68^{*}$ & $0.000^{* * *}$ & -0.10 & $0.000^{* * *}$ & -0.40 & $0.030^{* *}$ \\
\hline Singapore & -0.15 & $0.000^{* * * *}$ & $-0.77^{* *}$ & $0.000^{* * * *}$ & -0.44 & $0.000^{* * * *}$ & -0.37 & $0.001^{* * * *}$ & -0.26 & $0.001^{* * *}$ \\
\hline South Africa & -0.02 & $0.000^{* * * *}$ & 0.19 & $0.000^{* * * *}$ & 0.68 & 0.629 & 0.86 & 0.979 & $1.05^{*}$ & 0.739 \\
\hline South Korea & $0.84^{*}$ & 0.468 & 0.03 & $0.043^{* *}$ & $1.52^{* * * *}$ & 0.526 & -0.09 & 0.476 & $1.48^{* *}$ & 0.359 \\
\hline Taiwan & -0.25 & $0.000^{* * *}$ & $-0.76^{*}$ & $0.000^{* * * *}$ & 0.86 & 0.467 & -0.37 & $0.007^{* * * *}$ & $0.71^{*}$ & 0.500 \\
\hline Thailand & -0.13 & $0.000^{* * * *}$ & $-0.72^{* * *}$ & $0.000^{* * * *}$ & $-0.84^{* * *}$ & $0.000^{* * * *}$ & 0.48 & 0.466 & 0.72 & $0.015^{* * *}$ \\
\hline Uruguay & 0.00 & $0.000^{* * * *}$ & $-0.97^{*}$ & $0.000^{* * * *}$ & 0.07 & $0.001^{* * * *}$ & $-1.58^{* * * * *}$ & $0.000^{* * * *}$ & -0.10 & $0.000^{* * *}$ \\
\hline Vietnam & 0.23 & 0.110 & 0.51 & $0.018^{* *}$ & -0.26 & $0.026^{* *}$ & 0.44 & 0.466 & $-2.35^{* * *}$ & $0.000^{\text {**** }}$ \\
\hline
\end{tabular}

Notes: The OLS estimates of the slope coefficient in Eq. (1) are reported in column called $\hat{\beta}$. Newey-West standard errors are used to determine the significance level. The column called F-stat reports the p-values for the joint null hypothesis that $\alpha=0$ and $\beta=1$ in Eq. (1). The column "Consensus" shows the results for Consensus Economics dataset, and the column "FX4Casts" contain the results for FX4Casts dataset. The sample covers the period from January 2004 to December 2012.

* Significance at the $10 \%$ significance level, respectively.

** Significance at the $5 \%$ significance level, respectively.

${ }^{* * *}$ Significance at the $1 \%$ significance level, respectively.

\subsubsection{Orthogonality of expectations to lagged forecast errors}

The first orthogonality test that we use involves regressing the forecast error on its lagged value:

$$
s_{t+h}-s_{t+h, t}^{e}=\alpha+\beta\left(s_{t}-s_{t, t-h}^{e}\right)+u_{t+h}
$$

If the forecast errors are orthogonal to previous period forecast errors, the null of rationality (or orthogonality) implies that $\alpha=0$ and $\beta=0$ in Eq. (2).

Table 5 reports the results of estimating Eq. (2) for 3-, 12-, and 24-month ahead forecasts from both datasets. For each forecast horizon, the table reports the $p$-values for the joint test of $\alpha=0$ and $\beta=0$. At the 3-month ahead forecast horizon, we find strong evidence in favor of orthogonality of survey expectations for developed countries in both datasets. The evidence is mixed for developing countries. Using Consensus Economics data, the joint null hypothesis of orthogonality is rejected for 3 out of 10 developed countries (Australia, Canada, and New Zealand), and for 16 out of 23 developing countries at least at the 10 percent significance level. Using FX4Casts data, the joint null of orthogonality is rejected for 1 out of 10 developed countries (Australia), and for only 2 out of 23 developing countries (Argentina and Brazil). While there is strong evidence in favor of orthogonality of the forecast errors for developed countries in both datasets, there is much more evidence in favor of orthogonality for developing countries in FX4Casts dataset than Consensus Economics. Since the former dataset samples exclusively financial institutions, while the latter surveys a broader range of professionals, including 
Table 5

Tests of orthogonality to lagged forecast errors: $s_{t+h}-s_{t+h, t}^{e}=\alpha+\beta\left(s_{t}-s_{t, t-h}^{e}\right)+u_{t+h}$.

\begin{tabular}{|c|c|c|c|c|c|c|c|c|c|c|}
\hline \multicolumn{5}{|c|}{ Forecast horizon $h=3$} & \multicolumn{4}{|l|}{$h=12$} & \multirow{2}{*}{\multicolumn{2}{|c|}{$\begin{array}{l}h=24 \\
\text { Consensus }\end{array}$}} \\
\hline \multirow[b]{2}{*}{ Country } & \multicolumn{2}{|c|}{ Consensus } & \multirow{2}{*}{$\begin{array}{l}\text { FX4Casts } \\
\hat{\beta}\end{array}$} & \multirow[b]{2}{*}{ F-stat } & \multicolumn{2}{|l|}{ Consensus } & \multicolumn{2}{|l|}{ FX4Casts } & & \\
\hline & $\hat{\beta}$ & F-stat & & & $\hat{\beta}$ & F-stat & $\hat{\beta}$ & F-stat & $\hat{\beta}$ & F-stat \\
\hline \multicolumn{11}{|c|}{ A. Developed countries } \\
\hline Australia & $0.19^{*}$ & $0.065^{*}$ & $0.20^{*}$ & $0.072^{*}$ & $-0.48^{* *}$ & $0.000^{* * * *}$ & $-0.50^{*}$ & $0.016^{*}$ & $-0.58^{* * *}$ & $0.000^{* * *}$ \\
\hline Canada & $0.28^{* * *}$ & $0.004^{* * * *}$ & 0.15 & 0.111 & $-0.55^{* * *}$ & $0.000^{* * * *}$ & $-0.64^{* * *}$ & $0.000^{* * * *}$ & -0.20 & $0.000^{* * * *}$ \\
\hline Denmark & 0.09 & 0.692 & 0.14 & 0.390 & $-0.46^{* * *}$ & $0.000^{* * * *}$ & $0.46^{* * *}$ & $0.001^{* * * *}$ & -0.17 & 0.225 \\
\hline Euro Area & 0.08 & 0.709 & 0.13 & 0.463 & $-0.46^{* * *}$ & $0.000^{* * *}$ & $-0.46^{* * *}$ & $0.001^{* * *}$ & -0.17 & 0.234 \\
\hline Japan & $0.26^{* *}$ & 0.126 & -0.02 & 0.677 & $0.56^{* * *}$ & $0.001^{* * * *}$ & $0.42^{* *}$ & $0.013^{* *}$ & 0.01 & 0.471 \\
\hline New Zealand & $0.27^{*}$ & $0.016^{* *}$ & 0.24 & 0.162 & $-0.56^{* * *}$ & $0.000^{* * *}$ & $-0.54^{* * * *}$ & $0.000^{* * * *}$ & $-0.48^{* * * *}$ & $0.000^{* * * *}$ \\
\hline Norway & 0.14 & 0.547 & 0.07 & 0.837 & $-0.58^{* * *}$ & $0.012^{* *}$ & $-0.63^{* * *}$ & $0.007^{* * *}$ & -0.08 & 0.166 \\
\hline Sweden & $0.22^{\text {*** }}$ & 0.116 & 0.18 & 0.297 & $-0.42^{* *}$ & $0.044^{* *}$ & $-0.46^{* *}$ & $0.022^{* *}$ & $-0.33^{* * * *}$ & $0.010^{* * *}$ \\
\hline Switzerland & 0.16 & 0.431 & 0.08 & 0.564 & -0.11 & 0.341 & -0.19 & 0.363 & -0.32 & $0.022^{* *}$ \\
\hline U.K. & $0.22^{*}$ & 0.104 & 0.20 & 0.462 & -0.17 & 0.342 & $-0.29^{* * *}$ & $0.044^{* *}$ & -0.03 & 0.511 \\
\hline \multicolumn{11}{|c|}{ B. Developing countries } \\
\hline Argentina & 0.07 & 0.594 & 0.18 & $0.095^{*}$ & -0.28 & 0.141 & $-0.29^{*}$ & 0.151 & -0.06 & 0.810 \\
\hline Bangladesh & $0.37^{*}$ & $0.000^{* * * *}$ & 0.10 & 0.800 & 0.26 & 0.531 & $0.23^{*}$ & 0.208 & $-0.67^{* * *}$ & $0.000^{* * *}$ \\
\hline Bolivia & $0.63^{* * *}$ & $0.000^{* * *}$ & 0.26 & 0.106 & 0.22 & $0.000^{* * * *}$ & -0.18 & 0.164 & -0.17 & $0.000^{* * * *}$ \\
\hline Brazil & $0.27^{* * *}$ & $0.012^{* *}$ & $0.20^{*}$ & $0.096^{*}$ & -0.18 & $0.061^{*}$ & -0.25 & $0.070^{*}$ & -0.14 & $0.016^{* *}$ \\
\hline Chile & 0.07 & 0.331 & -0.02 & 0.900 & $-0.46^{* * *}$ & $0.000^{\text {**** }}$ & $-0.42^{\text {**** }}$ & $0.000^{* * * *}$ & $-0.40^{*}$ & $0.000^{* * * *}$ \\
\hline Colombia & $0.22^{*}$ & $0.026^{* *}$ & 0.04 & 0.599 & $-0.47^{* * *}$ & $0.000^{* * * *}$ & $-0.41^{* * * *}$ & $0.000^{* * * *}$ & -0.20 & $0.000^{* * *}$ \\
\hline Egypt & $0.35^{\text {**** }}$ & $0.000^{* * * *}$ & 0.03 & 0.219 & $-0.28^{* * * *}$ & $0.003^{* * * *}$ & $-0.27^{* * *}$ & $0.059^{*}$ & $-0.25^{\text {*** }}$ & $0.000^{* * * *}$ \\
\hline India & $0.22^{*}$ & $0.074^{*}$ & 0.05 & 0.304 & $-0.29^{*}$ & 0.131 & $-0.47^{\text {**** }}$ & $0.003^{* * *}$ & 0.15 & 0.405 \\
\hline Indonesia & $0.29^{*}$ & 0.158 & 0.08 & 0.171 & -0.28 & 0.391 & -0.30 & 0.330 & $-0.56^{* * * *}$ & $0.000^{* * *}$ \\
\hline Israel & $0.42^{\text {**** }}$ & $0.002^{* * * *}$ & 0.15 & 0.253 & -0.25 & $0.080^{*}$ & $-0.50^{* *}$ & $0.002^{* * * *}$ & -0.29 & $0.000^{* * * *}$ \\
\hline Mexico & 0.20 & 0.506 & 0.08 & 0.870 & $-0.30^{* * *}$ & $0.001^{* * *}$ & $-0.35^{*}$ & $0.026^{* *}$ & $-0.54^{* * *}$ & $0.013^{* * *}$ \\
\hline Nigeria & 0.24 & $0.000^{* * * *}$ & 0.05 & 0.688 & -0.05 & $0.047^{* *}$ & $-0.36^{* *}$ & $0.000^{* * * *}$ & $0.38^{* *}$ & $0.073^{*}$ \\
\hline Pakistan & 0.35 & $0.009^{* * *}$ & 0.34 & 0.206 & -0.15 & 0.130 & -0.16 & 0.346 & -0.17 & 0.640 \\
\hline Paraguay & $0.42^{\text {*** }}$ & $0.000^{* * * *}$ & 0.16 & 0.366 & $-0.34^{*}$ & $0.000^{* * * *}$ & $-0.51^{* * *}$ & $0.003^{* * *}$ & -0.32 & $0.000^{* * *}$ \\
\hline Peru & $0.39^{* *}$ & $0.003^{* * * *}$ & 0.16 & 0.260 & $-0.65^{* * *}$ & $0.000^{* * *}$ & $-0.61^{* * * *}$ & $0.000^{* * * *}$ & $-0.45^{* * *}$ & $0.000^{* * * *}$ \\
\hline Philippines & $0.28^{*}$ & $0.009^{* * * *}$ & 0.05 & 0.405 & -0.22 & $0.002^{* * *}$ & -0.25 & $0.002^{* * *}$ & $-0.39^{* *}$ & $0.007^{* * *}$ \\
\hline Singapore & $0.26^{* *}$ & $0.055^{*}$ & 0.11 & 0.272 & $-0.48^{* *}$ & $0.000^{* * * *}$ & $-0.48^{*}$ & $0.000^{* * * *}$ & $-0.80^{* * * *}$ & $0.000^{* * * *}$ \\
\hline South Africa & $0.25^{* * *}$ & $0.068^{*}$ & 0.06 & 0.790 & 0.03 & 0.866 & -0.20 & 0.731 & -0.06 & 0.801 \\
\hline South Korea & $0.30^{\text {**** }}$ & $0.028^{* *}$ & $0.21^{*}$ & 0.156 & -0.03 & 0.525 & -0.24 & 0.260 & -0.11 & $0.027^{* *}$ \\
\hline Taiwan & $0.20^{*}$ & 0.134 & 0.10 & 0.618 & -0.31 & 0.298 & -0.36 & 0.332 & -0.47 & $0.001^{\text {****}}$ \\
\hline Thailand & $0.28^{\text {*** }}$ & 0.032 & 0.14 & 0.454 & -0.25 & 0.269 & -0.21 & 0.212 & $-0.70^{* * * *}$ & $0.000^{* * *}$ \\
\hline Uruguay & $0.20^{*}$ & $0.013^{* *}$ & 0.08 & 0.443 & $-0.59^{* * *}$ & $0.000^{* * * *}$ & $-0.58^{* * * *}$ & $0.010^{* * * *}$ & $-0.19^{* * *}$ & $0.000^{* * * *}$ \\
\hline Vietnam & $0.25^{*}$ & 0.190 & $-0.21^{*}$ & 0.135 & 0.30 & 0.255 & 0.20 & 0.292 & 0.38 & $0.005^{* * *}$ \\
\hline
\end{tabular}

Notes: The OLS estimates of the slope coefficient in Eq. (2) are reported in column called $\hat{\beta}$. Newey-West standard errors are used to determine the significance level. The column called F-stat reports the p-values for the joint null hypothesis that $\alpha=0$ and $\beta=0$ in Eq. (2). The column "Consensus" shows the results for Consensus Economics dataset, and the column "FX4Casts" contain the results for FX4Casts dataset. The sample covers the period from January 2004 to December 2012.

* Significance at the $10 \%$ significance level, respectively.

** Significance at the $5 \%$ significance level, respectively.

*** Significance at the $1 \%$ significance level, respectively.

academicians, the focus of FX4Casts on financial companies might explain why their forecasts tend to be relatively more efficient for developing countries at the shorter forecast horizon.

As we expand the forecast horizon to 12 months, the number of rejections of the orthogonality null increases dramatically for developed countries. At the 12-month horizon, the joint null hypothesis of orthogonality is rejected for 8 out of 10 developed countries in Consensus Economics, and for 9 out of 10 developed countries in FX4Casts. For developing countries, the joint null of orthogonality is now rejected for 13 out of 23 currencies in both datasets. Thus, we find stronger evidence of forecast efficiency for developed countries at the 3-month horizon than at the 12-month horizon with both datasets. However, the results are mixed for developing countries, with the 3-month ahead forecasts being more rational than 12-month forecasts in FX4Casts, and less rational than 12-month forecasts in Consensus Economics.

As we expand the forecast horizon further to 24 months, the number of rejections decreases for developed countries and increases for developing countries. The joint null hypothesis of orthogonality is rejected for 5 out of 10 developed countries (Australia, Canada, New Zealand, Sweden, and Switzerland), and for 19 out of 23 developing countries in Consensus Economics. These results suggest that increasing the forecast horizon have a non-linear effect on the rationality of expectations across the forecast horizons, and that the forecasts for developed and developing countries behave differently.

\subsubsection{Orthogonality of expectations to lagged exchange rate changes}

The second test for orthogonality involves regressing the forecast error on the lagged actual exchange rate depreciation:

$$
s_{t+h}-s_{t+h, t}^{e}=\alpha+\beta\left(s_{t}-s_{t-1}\right)+u_{t+h}
$$


If the forecast errors are orthogonal to lagged actual exchange rate changes, then the null of rationality (or orthogonality) implies that $\alpha=0$ and $\beta=0$ in Eq. (3).

Table 6 reports the results of estimating Eq. (3) for 3-, 12, and 24-month ahead forecasts. At the 3-month horizon, we find evidence against orthogonality for all developed countries except Sweden in Consensus Economics, and only for Australia in FX4Casts. For developing countries, the joint null of orthogonality is rejected for 20 out of 23 currencies in Consensus Economics, and for 3 out of 23 currencies in FX4Casts. Thus, 3-month ahead expectations are more rational in FX4Casts than in Consensus Economics.

As the forecast horizon increases from 3 to 12 months, the evidence of orthogonality gets stronger in Consensus Economics data and weaker in FX4Casts. At the 12-month horizon, the joint null hypothesis of orthogonality is rejected for 4 out of 10 developed countries (Australia, Canada, Japan, and New Zealand) in Consensus Economics, and for 7 out of 10 developed countries (Australia, Canada, Denmark, Euro Area, Japan, Norway, and Sweden) in FX4Casts. For developing countries, the joint null of orthogonality is rejected for 10 out of 23 currencies in Consensus Economics, and for 7 out of 23 currencies in FX4Casts. Even though the evidence of orthogonality gets weaker with the forecast horizon in FX4Casts, FX4Casts forecasts are still relatively more efficient at predicting the exchange rates of developing currencies than Consensus Economics forecasts.

As we expand the forecast horizon further to 24 months, the number of rejections of the orthogonality increases, which implies that the forecasts become less efficient than at the 12 -month horizon. ${ }^{14}$ At the 24 -month horizon, the joint null hypothesis of orthogonality is rejected for 7 out of 10 developed countries (Australia, Canada, Denmark, the Euro Area, Japan, New Zealand, and Switzerland), and for 15 out of 23 developing countries with Consensus Economics. Thus, the results indicate that increasing the forecast horizon have a non-linear effect on the rationality of expectations across the forecast horizons, and that the forecasts for developed and developing countries follow a similar pattern.

\section{Forecasting performance of survey-based expectations}

In order to evaluate the forecasting performance of professional forecasters, it is necessary to choose a loss function that quantifies the cost associated with the forecast errors and to select an appropriate test statistic to conduct statistical inference. We apply two evaluation methods to assess the forecasting ability of survey-based exchange rate forecasts. The first approach is based on the differences between the mean-squared prediction errors (MSPEs) of competing forecasts. The second method relies on the direction-of-change comparison, where the forecasts are evaluated based on their ability to correctly predict the direction of change in the exchange rates.

\subsection{Tests based on the MSPE comparison}

Since the seminal work of Meese and Rogoff (1983), the mean-squared prediction error (MSPE) approach has become dominant in the exchange rate forecasting literature. Meese and Rogoff (1983) find that none of the empirical exchange rate models achieve lower root mean squared errors (RMSE) than a random walk, or a naïve no-change forecast. Their pessimistic finding has drawn substantial attention to the issue of exchange rate predictability. Multiple studies have assessed the forecasting performance of various candidate exchange rate models by using the random walk model as a benchmark. Summarizing the findings of rare studies that evaluate the accuracy of survey-based individual exchange rate forecasts, Jongen et al. (2008) conclude that "the random walk model remains pre-eminent." Among the two variants of the random walk benchmark, with and without the drift, the random walk without drift has been shown to be more difficult to outperform. Hence, we choose the driftless random walk as the benchmark model to evaluate the performance of survey forecasts.

Rossi (2013) surveys the literature on exchange rate predictability and discusses that the majority of studies in the exchange rate forecasting literature use either the Diebold and Mariano (1995) and West (1996), or the Clark and West (2006) tests for forecast evaluation. The Clark and West statistic is appropriate for evaluating models in population, since it tests whether the benchmark and the competing model are equivalent. Instead, the Diebold-Mariano and West statistic is suitable for evaluating forecasts, as it tests whether the forecasts from the random walk and the empirical model are equivalent. Since we do not have any information about the models used by the forecasters in both surveys, we use the Diebold-Mariano and West (DMW) test statistics to measure the forecast accuracy of survey forecasts against the driftless random walk.

The prediction errors of the random walk without drift and the survey forecasts are calculated as follows,

$$
\begin{aligned}
& \text { Random Walk without drift : } s_{t+h}-s_{t} \\
& \text { Survey Forecasts : } s_{t+h}-s_{t+h, t}^{e}
\end{aligned}
$$

For simplicity, let us focus on one-step-ahead forecasting. Assume that the sample size is $T$, and $P$ is equal to the number of forecasts. In our case, $T=P$. The one step ahead prediction for $y_{t+1}$ is 0 for the random walk without drift, and $s_{t+1, t}^{e}$ for the survey forecast. The respective forecast errors for the two forecasts are $\hat{e}_{1, t+1}=y_{t+1}$ and $\hat{e}_{2, t+1}=s_{t+1}-s_{t+1, t}^{e}$. Thus, the sample MSPEs for the two models become:

\footnotetext{
${ }^{14}$ At the same time, Consensus Economics forecasts at the 24-month horizon are still more efficient than at the 3-month horizon.
} 
Table 6

Tests of orthogonality to lagged actual exchange rate change: $s_{t+h}-s_{t+h, t}^{e}=\alpha+\beta\left(s_{t}-s_{t-1}\right)+u_{t+h}$.

\begin{tabular}{|c|c|c|c|c|c|c|c|c|c|c|}
\hline \multicolumn{5}{|c|}{ Forecast horizon $h=3$} & \multicolumn{4}{|l|}{$h=12$} & \multirow{2}{*}{\multicolumn{2}{|c|}{$\begin{array}{l}h=24 \\
\text { Consensus }\end{array}$}} \\
\hline \multirow[b]{2}{*}{ Country } & \multicolumn{2}{|c|}{ Consensus } & \multicolumn{2}{|c|}{ FX4Casts } & \multicolumn{2}{|c|}{ Consensus } & \multicolumn{2}{|l|}{ FX4Casts } & & \\
\hline & $\hat{\beta}$ & F-stat & $\hat{\beta}$ & F-stat & $\hat{\beta}$ & F-stat & $\hat{\beta}$ & F-stat & $\hat{\beta}$ & F-stat \\
\hline \multicolumn{11}{|c|}{ A. Developed countries } \\
\hline Australia & $0.61^{* * * *}$ & $0.000^{* * *}$ & 0.37 & $0.044^{* *}$ & -0.06 & $0.009^{* * *}$ & -0.40 & $0.092^{*}$ & -0.05 & $0.000^{* * *}$ \\
\hline Canada & $0.53^{* * * *}$ & $0.000^{* * * *}$ & 0.13 & 0.305 & 0.15 & $0.055^{*}$ & $-0.30^{*}$ & $0.099^{*}$ & 0.05 & $0.001^{* * * *}$ \\
\hline Denmark & $0.50^{* *}$ & $0.039^{* *}$ & 0.18 & 0.361 & -0.18 & 0.660 & $-0.53^{* *}$ & $0.072^{*}$ & $0.25^{* *}$ & $0.045^{* *}$ \\
\hline Euro Area & $0.50^{* *}$ & $0.042^{* *}$ & 0.15 & 0.524 & -0.19 & 0.645 & $-0.54^{* *}$ & $0.061^{*}$ & $0.25^{* *}$ & $0.048^{* *}$ \\
\hline Japan & $0.47^{* * * *}$ & $0.012^{* *}$ & 0.10 & 0.636 & $0.66^{* *}$ & $0.019^{* *}$ & $0.41^{*}$ & $0.073^{*}$ & $0.87^{* * * *}$ & $0.000^{* * *}$ \\
\hline New Zealand & $0.59^{* * * *}$ & $0.000^{* * * *}$ & 0.33 & 0.122 & 0.03 & $0.074^{*}$ & -0.42 & 0.194 & -0.18 & $0.000^{* * * *}$ \\
\hline Norway & $0.68^{* *}$ & $0.020^{* *}$ & 0.36 & 0.180 & -0.24 & 0.461 & $-0.56^{* *}$ & $0.045^{* *}$ & -0.03 & 0.262 \\
\hline Sweden & $0.50^{*}$ & 0.164 & 0.24 & 0.432 & -0.20 & 0.664 & $-0.59^{* * *}$ & $0.015^{* *}$ & 0.04 & 0.764 \\
\hline Switzerland & $0.44^{* * *}$ & $0.071^{*}$ & 0.11 & 0.445 & 0.07 & 0.354 & -0.26 & 0.333 & 0.30 & $0.004^{* * *}$ \\
\hline U.K. & $0.55^{* * *}$ & $0.023^{* *}$ & 0.41 & 0.271 & 0.13 & 0.632 & -0.33 & 0.265 & 0.10 & 0.544 \\
\hline \multicolumn{11}{|c|}{ B. Developing countries } \\
\hline Argentina & $0.38^{*}$ & 0.105 & $0.48^{* *}$ & $0.007^{* * *}$ & $-0.90^{* *}$ & $0.072^{*}$ & 0.08 & 0.406 & $-1.58^{* *}$ & $0.064^{*}$ \\
\hline Bangladesh & $0.72^{* * * *}$ & $0.001^{* * * *}$ & -0.08 & 0.908 & $1.59^{*}$ & 0.120 & -0.39 & 0.186 & 0.31 & 0.837 \\
\hline Bolivia & $1.92^{* * * *}$ & $0.000^{* * * *}$ & 0.17 & $0.070^{*}$ & $2.86^{* *}$ & $0.000^{* * *}$ & 0.34 & $0.028^{* *}$ & 0.13 & $0.000^{* * *}$ \\
\hline Brazil & $0.78^{* * * *}$ & $0.002^{* * * *}$ & 0.33 & 0.145 & 0.28 & 0.118 & -0.22 & 0.346 & 0.14 & $0.006^{* * *}$ \\
\hline Chile & $0.35^{*}$ & $0.020^{* *}$ & 0.09 & 0.605 & -0.04 & $0.022^{* *}$ & $-0.37^{*}$ & $0.015^{* *}$ & $-0.20^{*}$ & $0.000^{* * * *}$ \\
\hline Colombia & $0.67^{* *}$ & $0.000^{* * * *}$ & -0.02 & 0.751 & 0.14 & $0.004^{* * * *}$ & $-0.48^{*}$ & $0.010^{* * *}$ & -0.06 & $0.000^{* * * *}$ \\
\hline Egypt & $0.81^{\text {**** }}$ & $0.000^{* * * * *}$ & 0.10 & 0.125 & $0.96^{*}$ & $0.000^{* * * *}$ & -0.69 & 0.286 & $1.64^{* * *}$ & $0.000^{* * *}$ \\
\hline India & $0.61^{*: * *}$ & $0.018^{* *}$ & 0.08 & 0.311 & $0.83^{* *}$ & $0.078^{*}$ & 0.22 & 0.120 & -0.39 & 0.130 \\
\hline Indonesia & $0.64^{* * *}$ & $0.018^{* *}$ & 0.01 & 0.491 & 0.36 & 0.325 & -0.36 & 0.413 & 0.06 & 0.864 \\
\hline Israel & $0.85^{* * * *}$ & $0.000^{* * *}$ & 0.06 & 0.742 & 0.17 & 0.368 & $-0.57^{*}$ & 0.102 & 0.27 & $0.030^{* *}$ \\
\hline Mexico & $0.79^{* * * *}$ & $0.005^{* * *}$ & 0.37 & 0.496 & 0.33 & 0.475 & -0.16 & 0.787 & 0.28 & $0.065^{*}$ \\
\hline Nigeria & $0.72^{* * * *}$ & $0.000^{* * * *}$ & $0.26^{*}$ & 0.122 & $0.68^{* * *}$ & $0.023^{* *}$ & -0.04 & 0.980 & 0.85 & 0.331 \\
\hline Pakistan & 0.84 & $0.006^{* * *}$ & 0.55 & 0.192 & 1.03 & 0.267 & 0.49 & 0.165 & 0.18 & 0.297 \\
\hline Paraguay & $1.11^{* * *}$ & $0.000^{* * * *}$ & $0.33^{* * *}$ & $0.073^{*}$ & 0.28 & $0.000^{* * * *}$ & -0.67 & 0.173 & 0.68 & $0.000^{* * *}$ \\
\hline Peru & $0.79^{* * *}$ & $0.002^{* * *}$ & 0.01 & 0.538 & -0.32 & $0.006^{* * *}$ & $-0.88^{*}$ & $0.001^{* * * *}$ & -0.27 & $0.000^{* * *}$ \\
\hline Philippines & $0.73^{* * * *}$ & $0.000^{* * * *}$ & 0.13 & 0.344 & 0.71 & 0.255 & 0.08 & 0.611 & 0.38 & $0.093^{*}$ \\
\hline Singapore & $0.63^{* * * *}$ & $0.003^{* * * *}$ & 0.14 & 0.477 & -0.11 & 0.321 & $-0.50^{* *}$ & $0.011^{* * *}$ & -0.05 & $0.000^{* * * *}$ \\
\hline South Africa & $0.42^{* * *}$ & $0.027^{* * *}$ & 0.18 & 0.411 & 0.34 & 0.284 & -0.03 & 0.981 & 0.13 & 0.626 \\
\hline South Korea & 0.38 & 0.256 & 0.17 & 0.829 & 0.34 & 0.328 & -0.25 & 0.267 & 0.22 & 0.135 \\
\hline Taiwan & $0.58^{* * *}$ & $0.024^{* *}$ & 0.24 & 0.489 & -0.13 & 0.432 & $-0.54^{* *}$ & $0.100^{*}$ & -0.03 & 0.571 \\
\hline Thailand & $0.55^{* * *}$ & $0.036^{* * *}$ & 0.15 & 0.517 & 0.29 & 0.573 & 0.16 & 0.578 & -0.13 & $0.002^{\text {**** }}$ \\
\hline Uruguay & 0.48 & $0.010^{* * *}$ & $0.37^{*}$ & 0.103 & 0.02 & $0.004^{* * * *}$ & $-0.70^{*}$ & $0.058^{*}$ & 0.03 & $0.000^{* * * *}$ \\
\hline Vietnam & 0.27 & 0.377 & -0.08 & 0.294 & 0.40 & 0.171 & 0.18 & 0.456 & $1.52^{* * *}$ & $0.000^{* * *}$ \\
\hline
\end{tabular}

Notes: The OLS estimates of the slope coefficient in Eq. (3) are reported in column called $\hat{\beta}$. Newey-West standard errors are used to determine the significance level. The column called F-stat reports the p-values for the joint null hypothesis that $\alpha=0$ and $\beta=0$ in Eq. (3). The column "Consensus" shows the results for Consensus Economics dataset, and the column "FX4Casts" contain the results for FX4Casts dataset. The sample covers the period from January 2004 to December 2012.

* Significance at the $10 \%$ significance level, respectively.

** Significance at the $5 \%$ significance level, respectively.

*** Significance at the $1 \%$ significance level, respectively.

$$
\hat{\sigma}_{1}^{2}=P^{-1} \sum_{t=T-P+1}^{T} y_{t+1}^{2} \text { and } \hat{\sigma}_{2}^{2}=P^{-1} \sum_{t=T-P+1}^{T}\left(s_{t+1}-s_{t+1, t}^{e}\right)^{2}
$$

Diebold and Mariano (1995) and West (1996) construct a $t$-type statistics which is assumed to be asymptotically normal, and the population MSPEs are equal under the null. Defining the following equations,

$$
\begin{aligned}
& \hat{f}_{t}=\hat{e}_{1, t}^{2}-\hat{e}_{2, t}^{2} \\
& \bar{f}=P^{-1} \sum_{t=T-P+1}^{T} \hat{f}_{t+1}=\hat{\sigma}_{1}^{2}-\hat{\sigma}_{2}^{2} \\
& \hat{V}=P^{-1} \sum_{t=T-P+1}^{T}\left(\hat{f}_{t+1}-\bar{f}\right)^{2}
\end{aligned}
$$

The DMW test statistic is

$$
D M W=\frac{\bar{f}}{\sqrt{P^{-1} \hat{V}}}
$$


Table 7

Tests of predictive accuracy.

\begin{tabular}{|c|c|c|c|c|c|c|c|c|c|c|}
\hline \multicolumn{5}{|c|}{ Forecast horizon $h=3$} & \multicolumn{4}{|l|}{$h=12$} & \multirow{2}{*}{\multicolumn{2}{|c|}{$\begin{array}{l}h=24 \\
\text { Consensus }\end{array}$}} \\
\hline \multirow[b]{2}{*}{ Country } & \multicolumn{2}{|l|}{ Consensus } & \multicolumn{2}{|l|}{ FX4casts } & \multicolumn{2}{|l|}{ Consensus } & \multicolumn{2}{|l|}{ FX4casts } & & \\
\hline & MSPE Ratio & $D M W$ & MSPE Ratio & $D M W$ & MSPE Ratio & $D M W$ & MSPE Ratio & $D M W$ & MSPE Ratio & $D M W$ \\
\hline \multicolumn{11}{|c|}{ A. Developed countries } \\
\hline Australia & 1.274 & -3.116 & 1.041 & -1.167 & 0.984 & 0.233 & 0.972 & 0.468 & 1.056 & -0.714 \\
\hline Canada & 1.192 & -2.145 & 1.057 & -1.188 & 0.837 & $2.604^{* * * *}$ & 0.831 & $3.138^{* * * *}$ & 0.907 & $1.430^{*}$ \\
\hline Denmark & 1.096 & -1.204 & 1.105 & -1.986 & 0.785 & $3.142^{* * * *}$ & 0.935 & 0.866 & 0.531 & $4.551^{* * * *}$ \\
\hline Euro Area & 1.101 & -1.255 & 1.066 & -1.165 & 0.784 & $3.159^{* * *}$ & 0.927 & 0.981 & 0.534 & $4.530^{* * * *}$ \\
\hline Japan & 1.374 & -3.560 & 1.200 & -3.866 & 1.888 & -6.457 & 1.590 & -5.672 & 1.234 & -2.139 \\
\hline New Zealand & 1.305 & -2.753 & 1.088 & -1.488 & 1.068 & -0.673 & 1.008 & -0.132 & 1.088 & -0.777 \\
\hline Norway & 1.132 & -1.631 & 1.021 & -0.687 & 0.659 & $4.972^{* * * *}$ & 0.859 & $2.808^{* * * *}$ & 0.566 & $5.126^{* * * *}$ \\
\hline Sweden & 1.169 & -2.015 & 1.061 & -1.418 & 0.729 & $4.044^{* * * *}$ & 0.876 & $2.207^{* *}$ & 0.458 & $4.967^{* * * *}$ \\
\hline Switzerland & 1.155 & -1.462 & 1.106 & -1.784 & 1.014 & -0.156 & 1.154 & -2.015 & 1.018 & -0.214 \\
\hline U.K. & 1.080 & -1.055 & 1.051 & -0.816 & 0.713 & $3.840^{* * * *}$ & 0.790 & $2.622^{* * * *}$ & 0.650 & $5.635^{* * * *}$ \\
\hline \multicolumn{11}{|c|}{ B. Developing countries } \\
\hline Argentina & 0.621 & $3.146^{* * *}$ & 0.838 & $2.545^{* * *}$ & 0.614 & $2.941^{* * * *}$ & 0.684 & $4.099^{* * *}$ & 0.512 & $4.593^{* * * *}$ \\
\hline Bangladesh & 1.525 & -3.784 & 0.877 & 0.919 & 0.812 & $1.767^{* *}$ & 0.658 & $3.914^{* * *}$ & 0.478 & $4.228^{* * *}$ \\
\hline Bolivia & 2.356 & -5.701 & 0.908 & $1.519^{*}$ & 2.197 & -8.874 & 0.867 & $1.568^{*}$ & 3.268 & -10.747 \\
\hline Brazil & 1.218 & -3.009 & 1.055 & -0.986 & 1.276 & -3.820 & 1.213 & -4.754 & 1.817 & -6.859 \\
\hline Chile & 1.014 & -0.256 & 0.952 & $1.468^{*}$ & 0.997 & 0.040 & 0.970 & 0.604 & 1.286 & -3.510 \\
\hline Colombia & 1.295 & -2.813 & 1.019 & -0.428 & 1.357 & -3.071 & 1.052 & -0.954 & 2.041 & -9.386 \\
\hline Egypt & 1.849 & -5.293 & 1.084 & -1.112 & 1.802 & -6.003 & 1.547 & -2.537 & 1.884 & -4.630 \\
\hline India & 1.173 & -1.612 & 1.066 & -1.800 & 1.200 & -3.069 & 1.205 & -3.669 & 1.190 & -2.388 \\
\hline Indonesia & 1.286 & -3.629 & 1.091 & -2.507 & 0.947 & 0.752 & 1.121 & -2.103 & 0.636 & $3.151^{* * * *}$ \\
\hline Israel & 1.270 & -2.642 & 1.078 & -2.399 & 1.003 & -0.034 & 1.316 & -5.996 & 1.166 & -2.286 \\
\hline Mexico & 1.145 & -1.218 & 1.109 & -1.558 & 0.932 & 1.070 & 0.977 & 0.469 & 0.865 & $1.523^{*}$ \\
\hline Nigeria & 1.751 & -2.931 & 1.047 & -0.798 & 1.337 & -2.479 & 1.241 & -3.905 & 1.812 & -2.914 \\
\hline Pakistan & 0.953 & 0.318 & 0.869 & $3.093^{* * *}$ & 0.692 & $4.294^{* * * *}$ & 0.742 & $4.623^{* * *}$ & 0.520 & $6.572^{* * * *}$ \\
\hline Paraguay & 1.534 & -2.785 & 1.000 & -0.006 & 1.549 & -3.884 & 1.111 & -2.123 & 2.304 & -8.964 \\
\hline Peru & 1.601 & -3.068 & 1.012 & -0.284 & 1.375 & -4.935 & 1.186 & -2.110 & 1.579 & -5.841 \\
\hline Philippines & 1.257 & -2.576 & 0.986 & 0.284 & 1.205 & -3.508 & 1.019 & -0.255 & 1.230 & -3.712 \\
\hline Singapore & 1.235 & -1.812 & 1.087 & -1.292 & 0.839 & $2.012^{* * *}$ & 0.771 & $2.936^{* * *}$ & 0.536 & $9.120^{* * * *}$ \\
\hline South Africa & 1.212 & -2.357 & 1.036 & -0.827 & 0.921 & 0.850 & 0.932 & 1.025 & 0.725 & $2.988^{\text {*** }}$ \\
\hline South Korea & 0.968 & 0.342 & 1.033 & -1.053 & 0.938 & 0.810 & 1.062 & -1.383 & 0.911 & $1.521^{*}$ \\
\hline Taiwan & 1.289 & -2.592 & 1.126 & -2.211 & 0.936 & 0.582 & 1.121 & -1.080 & 0.824 & 1.193 \\
\hline Thailand & 1.312 & 83.241 & 1.267 & -3.492 & 1.142 & -2.084 & 0.944 & 0.942 & 0.747 & $5.781^{* * * *}$ \\
\hline Uruguay & 1.459 & -3.006 & 1.087 & -2.399 & 1.605 & -5.087 & 1.372 & -5.109 & 2.735 & -9.857 \\
\hline Vietnam & 0.915 & 0.564 & 0.837 & $2.068^{* *}$ & 0.668 & $4.110^{\text {*** }}$ & 0.568 & $5.459^{* * *}$ & 0.763 & $6.345^{* * *}$ \\
\hline
\end{tabular}

Notes: The table reports the ratio of the out-of-sample MSPEs of survey forecasts to that of the random walk model without drift and the DMW statistics for the test of equal forecasting ability between the forecasts. The MSPE Ratios below 1 are marked in bold to indicate that the MSPE of survey forecasts is lower than that of the random walk. Significant test statistics indicates rejection of the null of equal forecasting ability. The column "Consensus" shows the results for Consensus Economics dataset, and the column "FX4Casts" contain the results for FX4Casts dataset. The sample covers the period from January 2004 to December 2012.

* Significance at the $10 \%$ significance level, respectively.

** Significance at the $5 \%$ significance level, respectively.

*** Significance at the $1 \%$ significance level, respectively.

Table 7 reports the ratio of the MSPEs of survey forecasts to that of the random walk without drift and the DMW statistics for the test of equal forecasting ability. The MSPE Ratio below 1 indicates that the MSPE of survey forecasts is lower than that of the driftless random walk. At the 3-month horizon, we find no evidence of forecasting ability for developed countries. For developing countries, we find weak evidence of forecasting ability for developing countries in both datasets, with FX4Casts expectations being more accurate than Consensus Economics. For developed countries, all the MSPE ratios are greater than one and the DMW statistics are insignificant, indicating that the forecasts from both datasets are not able to outperform the random walk model at the short horizon. Using Consensus Economics forecasts, the MSPEs for 4 out 23 developing countries are lower than MSPEs of the random walk, however the differences are significant based on the DMW statistic only for Argentina. There is slightly more evidence of forecasting ability in the short-run for developing countries in FX4Casts. The MSPE ratio is less than one for 7 out of 23 currencies, and the null of equal forecasting performance is rejected for 5 out of 23 currencies.

As the forecast horizon increases, the forecasting ability of survey forecasts improves for both groups of countries. At the 12-month horizon, the MSPE ratio is less than one for 7 out of 10 developed countries (Australia, Canada, Denmark, Euro Area, Norway, Sweden, and the U.K.) in both datasets. The forecasts significantly outperform the random walk based on the DMW statistics at least at the 10 percent significance level for 6 out of 10 developed countries (Canada, Denmark, Euro Area, Norway, Sweden, and the U.K.) in Consensus Economics, and for 4 out of 10 developed countries (Canada, Norway, Sweden, and the U.K.) in FX4Casts data. For developing countries, the MSPE ratio is less than one for 11 out of 23 currencies 
in Consensus Economics, and for 10 out of 23 developing countries in FX4Casts data. The forecasts significantly outperform the random walk null for 5 out of 23 currencies in Consensus Economics, and for 6 out of 23 developing countries in FX4Casts data.

At the 24-month horizon, the MSPE ratio is less than one for 6 out of 10 developed countries (Canada, Denmark, Euro Area, Norway, Sweden, and the U.K.), and for 11 out of 23 developing countries in Consensus Economics. Survey forecasts significantly outperform the driftless random walk at least at the 10 percent significance level for the same 6 out of 10 developed countries, and for 10 out of 23 developing countries.

Overall, two observations can be made from the results in Table 7. First, the forecasting ability of survey forecasters increases with the forecast horizon. Second, survey forecasts are somewhat more accurate for developing than for developed countries at the short forecast horizon, especially in FX4Casts dataset. To further examine the forecasting power of survey expectations, we evaluate the performance of professional forecasters based on the test of directional accuracy.

\subsection{Tests based on the directional accuracy}

To evaluate the directional accuracy of survey forecasts, we rely on the nonparametric test developed by Pesaran and Timmermann (1992). The test statistic is based on the proportion of times that the direction of change in the exchange rate is correctly forecasted. Under the null, the actual and predicted values of the exchange rate change are independently distributed, so that the model have no ability to predict the sign of actual values.

If $\hat{y}_{t}$ is the predicted value of $y_{t}, p_{y}=\operatorname{Pr}\left(y_{t}>0\right), p_{\hat{y}}=\operatorname{Pr}\left(\hat{y}_{t}>0\right)$, and $\hat{p}$ is the proportion of times that the sign of $y_{t}$ is correctly forecasted, the Pesaran and Timmermann test (PT test, henceforth) statistic, $S_{n}$ is

$$
S_{n}=\frac{\hat{p}-\hat{p}_{*}}{\left(\hat{v}(\hat{p})-\hat{v}\left(\hat{p}_{*}\right)\right)^{1 / 2}}
$$

where $\hat{p}_{*}=p_{y} p_{\hat{y}}+\left(1-p_{y}\right)\left(1-p_{\hat{y}}\right)$

$$
\begin{aligned}
& \hat{v}(\hat{p})=\frac{1}{n} \hat{p}_{*}\left(1-\hat{p}_{*}\right) \\
& \hat{v}\left(\hat{p}_{*}\right)=\frac{1}{n}\left(2 p_{y}-1\right)^{2} p_{\hat{y}}\left(1-p_{\hat{y}}\right)+\frac{1}{n}\left(2 p_{\hat{y}}-1\right)^{2} p_{y}\left(1-p_{y}\right)+4 \frac{1}{n^{2}} p_{y} p_{\hat{y}}\left(1-p_{\hat{y}}\right)\left(1-p_{y}\right)
\end{aligned}
$$

The null hypothesis of the PT test is that $y_{t}$ and $\hat{y}_{t}$ are distributed independently, and the two-sided test statistic in Eq. (8), $S_{n}$, converges to the standard normal distribution under the null hypothesis.

Table 8 reports the proportion of survey forecasts that correctly predict the sign of actual exchange rate change (PCS), where the ratio greater than 0.5 indicates that more than half of the forecasts are successful, and the respective PT test statistics for 3-, 12-, and 24-month ahead forecasts from the two datasets. ${ }^{15}$ At the 3-month horizon, the success ratios are greater than 0.5 for 6 out of 10 developed countries (Denmark, Euro Area, Norway, Sweden, Switzerland, and the U.K.) in Consensus Economics, and for 4 out of 10 developed countries (Canada, Denmark, Norway, and the U.K.) in FX4Casts. The PT test is significant for 1 out of 10 developed countries (the U.K.) in Consensus Economics, and for no developed countries in FX4Casts. For developing countries, the proportion of the forecasts with the correct sign is greater than 0.5 for 11 out of 23 currencies in Consensus Economics, and for 16 out of 23 currencies in FX4Casts. The null of no directional accuracy is rejected for 4 out of 23 developing countries in Consensus Economics, and for 1 out of 24 developing countries in FX4Casts. Overall, the forecasts from both surveys show that the evidence of directional accuracy is weak at the 3-month ahead forecast horizon.

As the forecast horizon increases, the directional accuracy of survey forecasts improves for developed countries, and stays about the same for developing countries. At the 12-month ahead horizon, the proportion of forecasts with the correct sign is greater than 0.5 for 7 out of 10 developed countries (Canada, Denmark, Euro Area, Norway, Sweden, Switzerland, and the U. K.) in Consensus Economics, and for 9 out of 10 developed countries (all countries except Japan) in FX4Casts. The PT statistic is significant at least at the 10 percent level for 9 out of 10 developed countries (all countries except Japan) in Consensus Economics, and for 6 out of 10 developed countries (Canada, Denmark, Euro Area, Norway, Sweden, and the U.K.) in FX4Casts. For developing countries, the proportion of forecasts with the correct sign is greater than 0.5 for 12 out of 23 currencies in Consensus Economics, and for 16 out of 23 currencies in FX4Casts. The PT statistic is significant at least at the 10 percent level for 2 out of 23 developing countries in Consensus Economics, and for 3 out of 23 developing countries in FX4Casts.

At the 24-month horizon, the proportion of forecasts with the correct sign is greater than 0.5 for 8 out of 10 developed countries (all countries except Australia and Japan), and for 12 out of 23 developing countries in Consensus Economics. The PT statistic is significant at least at the 10 percent level for 7 out of 10 developed countries (Australia, Denmark, Euro Area, New Zealand, Norway, Sweden, and the U.K.), and for 3 out of 23 developing countries. Thus, the evidence of directional accuracy at the 24-month horizon is about the same as at the 12-month horizon for all currencies.

\footnotetext{
15 The PT test statistics cannot be calculated for Pakistan at the 12-month forecast horizon, and for Argentina, Bangladesh, Egypt, Pakistan, Paraguay, South Korea, Uruguay, and Vietnam at the 24-month forecast horizon. Perpetual depreciation of the Vietnamese dong against the U.S. dollar or consistent expectation of the depreciation for the other currencies make the denominator in Eq. (8) equal to 0.
} 
Table 8

Tests of directional accuracy.

\begin{tabular}{|c|c|c|c|c|c|c|c|c|c|c|}
\hline \multicolumn{5}{|c|}{ Forecast horizon $h=3$} & \multicolumn{4}{|l|}{$h=12$} & \multirow{2}{*}{\multicolumn{2}{|c|}{$\begin{array}{l}h=24 \\
\text { Consensus }\end{array}$}} \\
\hline \multirow[b]{2}{*}{ Country } & \multicolumn{2}{|c|}{ Consensus } & \multicolumn{2}{|c|}{ FX4casts } & \multicolumn{2}{|c|}{ Consensus } & \multicolumn{2}{|c|}{ FX4casts } & & \\
\hline & PCS & $P T$ & PCS & $P T$ & PCS & $P T$ & PCS & $P T$ & PCS & $P T$ \\
\hline \multicolumn{11}{|c|}{ A. Developed countries } \\
\hline Australia & 0.429 & -0.746 & 0.486 & -0.278 & 0.417 & $2.389^{* *}$ & 0.563 & 1.253 & 0.417 & $2.350^{* *}$ \\
\hline Canada & 0.467 & -0.467 & 0.533 & 0.254 & 0.531 & $1.995^{* * *}$ & 0.802 & $5.901^{* * * *}$ & 0.512 & 1.481 \\
\hline Denmark & 0.514 & 0.338 & 0.505 & 0.154 & 0.688 & $3.819^{* * * *}$ & 0.646 & $3.009^{* * *}$ & 0.690 & $4.114^{* * *}$ \\
\hline Euro Area & 0.505 & 0.088 & 0.495 & -0.085 & 0.688 & $3.797^{* * * *}$ & 0.656 & $3.186^{* * *}$ & 0.679 & $3.883^{* * *}$ \\
\hline Japan & 0.457 & -1.112 & 0.362 & -2.938 & 0.354 & -3.268 & 0.344 & -3.480 & 0.405 & -3.546 \\
\hline New Zealand & 0.429 & -0.556 & 0.467 & -0.697 & 0.458 & $2.015^{* *}$ & 0.521 & 0.429 & 0.512 & $2.339^{* *}$ \\
\hline Norway & 0.543 & 0.424 & 0.543 & 0.133 & 0.750 & $4.302^{* * *}$ & 0.667 & $2.240^{* *}$ & 0.726 & $3.781^{\text {**** }}$ \\
\hline Sweden & 0.505 & -0.232 & 0.495 & -0.434 & 0.750 & $4.479^{* * * *}$ & 0.656 & $2.143^{* *}$ & 0.750 & $4.390^{* * * *}$ \\
\hline Switzerland & 0.533 & 0.664 & 0.467 & -0.708 & 0.594 & $2.132^{* *}$ & 0.510 & 0.509 & 0.536 & 0.650 \\
\hline U.K. & 0.600 & $2.374^{* * *}$ & 0.533 & 0.711 & 0.688 & $3.706^{* * *}$ & 0.708 & $4.149^{* * *}$ & 0.726 & $4.446^{* * * *}$ \\
\hline \multicolumn{11}{|c|}{ B. Developing countries } \\
\hline Argentina & 0.752 & $2.030^{* *}$ & 0.638 & -0.055 & 0.885 & -0.345 & 0.760 & 0.107 & 0.952 & NA \\
\hline Bangladesh & 0.638 & -0.180 & 0.629 & 0.545 & 0.802 & -0.485 & 0.792 & 0.329 & 0.857 & NA \\
\hline Bolivia & 0.152 & -0.977 & 0.410 & -3.501 & 0.156 & -0.865 & 0.438 & -2.055 & 0.155 & 0.652 \\
\hline Brazil & 0.505 & 1.014 & 0.457 & -1.168 & 0.365 & -0.213 & 0.406 & -1.466 & 0.393 & 1.323 \\
\hline Chile & 0.562 & $1.786^{*}$ & 0.562 & 0.611 & 0.458 & $2.692^{* * * *}$ & 0.688 & $2.796^{* *}$ & 0.310 & 0.911 \\
\hline Colombia & 0.457 & 0.290 & 0.610 & 1.412 & 0.375 & 0.583 & 0.625 & 0.093 & 0.238 & 0.894 \\
\hline Egypt & 0.457 & -1.288 & 0.705 & $4.301^{* * * *}$ & 0.375 & -2.246 & 0.688 & $3.839^{* * * *}$ & 0.405 & NA \\
\hline India & 0.438 & -1.702 & 0.495 & -1.087 & 0.500 & 0.147 & 0.490 & -2.253 & 0.464 & -0.697 \\
\hline Indonesia & 0.486 & -0.236 & 0.486 & -0.647 & 0.563 & 1.602 & 0.448 & -1.300 & 0.643 & $2.710^{* * * *}$ \\
\hline Israel & 0.371 & -2.446 & 0.410 & -1.991 & 0.510 & 1.229 & 0.229 & -5.237 & 0.393 & 0.155 \\
\hline Mexico & 0.505 & 0.769 & 0.514 & 0.511 & 0.542 & $1.914^{* * *}$ & 0.542 & 1.351 & 0.595 & $1.957^{*}$ \\
\hline Nigeria & 0.419 & -1.109 & 0.514 & 1.128 & 0.427 & -1.583 & 0.615 & $2.495^{* *}$ & 0.524 & -0.124 \\
\hline Pakistan & 0.771 & -0.739 & 0.667 & -0.752 & 0.979 & NA & 0.833 & -0.594 & 1.000 & NA \\
\hline Paraguay & 0.410 & 0.309 & 0.543 & -0.304 & 0.375 & 1.064 & 0.469 & -1.995 & 0.155 & NA \\
\hline Peru & 0.371 & -2.657 & 0.619 & -1.099 & 0.406 & -0.856 & 0.604 & -0.723 & 0.226 & -0.244 \\
\hline Philippines & 0.457 & -0.105 & 0.552 & -0.074 & 0.417 & -1.655 & 0.615 & -1.011 & 0.417 & 0.041 \\
\hline Singapore & 0.581 & -0.579 & 0.410 & -9.403 & 0.677 & -2.136 & 0.729 & -2.284 & 0.893 & -0.434 \\
\hline South Africa & 0.581 & $2.281^{* * *}$ & 0.505 & -0.288 & 0.594 & 1.088 & 0.583 & -0.127 & 0.750 & $3.235^{* * * *}$ \\
\hline South Korea & 0.543 & -0.393 & 0.562 & -0.692 & 0.635 & -0.850 & 0.635 & -1.251 & 0.583 & 0.062 \\
\hline Taiwan & 0.533 & -0.209 & 0.524 & -1.877 & 0.552 & -1.495 & 0.542 & -2.341 & 0.690 & NA \\
\hline Thailand & 0.438 & -1.845 & 0.381 & -2.770 & 0.448 & -4.030 & 0.500 & -0.548 & 0.762 & 1.538 \\
\hline Uruguay & 0.362 & -0.739 & 0.543 & -1.596 & 0.344 & -1.187 & 0.438 & -3.557 & 0.143 & NA \\
\hline Vietnam & 0.752 & $1.953^{*}$ & 0.724 & 0.486 & 0.844 & -0.818 & 0.875 & -0.364 & 0.952 & NA \\
\hline
\end{tabular}

Notes: The table reports the ratio of the proportion of forecasts that have correct sign (PCS) and the PT statistics for the test of directional accuracy of the forecasts. The PCS statistics marked in bold indicate that more than half of the forecasts are successful at predicting the sign of the exchange rate change. Significant test statistics indicate rejection of the null of independence between the actual and predicted exchange rate changes. (NA) denotes that the PT test statistics cannot be calculated for that specific currency. The column "Consensus" shows the results for Consensus Economics dataset, and the column "FX4Casts" contain the results for FX4Casts dataset. The sample covers the period from January 2004 to December 2012

* Significance at the $10 \%$ significance level, respectively.

** Significance at the $5 \%$ significance level, respectively.

*** Significance at the $1 \%$ significance level, respectively.

\subsection{Economic value of survey forecasts}

In addition to evaluating the performance of exchange rate forecasts with statistical measures, we apply two statistics to assess the economic value of survey expectations. First, we provide the Directional Value (DV) statistic developed by Blaskowitz and Herwartz (2011) that integrates the predicted direction of the exchange rate change with its magnitude:

$$
D V_{h}=\frac{\sum_{t=T-P+1}^{T}\left|s_{t+h, t}^{e}-s_{t}\right| . D A_{t+h, t}}{\sum_{t=T-P+1}^{T}\left|s_{t+h, t}-s_{t}\right|}
$$

where $D A$ is equal to 1 , if the predicted sign is correct, and 0 otherwise, and $h$ is the forecast horizon. While the PT test statistic examines the directional accuracy of survey forecasts and is robust to outlying forecasts, it disregards the magnitude of the realized directional movements. In contrast, the DV statistic measures the economic value of the forecasts by accounting for the size of the predicted directional movements.

Second, we report the Sharpe ratio, defined as the annualized excess return per unit of risk, to measure the risk-adjusted economic value of the forecasts. We use the buy and hold trading strategy provided in Gençay (1998) to calculate the annualized excess return of the forecasts. Trading signals in the buy and hold strategy are based on the spot rate. A prediction of an increase in $s_{t}$ (appreciation of the dollar) is described as a buying signal, and a decrease in $s_{t}$ (depreciation of the dollar) is 
described as a selling signal. The investor buys/sells the investment currency, and holds it at least until the end of the forecast horizon. The Sharpe ratio (SR) is defined as follows:

$$
\begin{aligned}
& S R_{h}=\frac{x \bar{s}}{\sigma_{x s}} \\
& x \bar{S}=P^{-1} x S \\
& x S=\sum_{t=T-P+1}^{T}\left(s_{t+h, t}-s_{t}\right) \cdot \operatorname{sign}\left(s_{t+h, t}^{e}-s_{t}\right)
\end{aligned}
$$

where $x s$ is the excess return of the trading strategy and $\sigma_{x s}$ is the standard deviation of the excess return.

Table 9 reports the Directional Value (DV) statistics and the Sharpe ratios for 3-, 12-, and 24-month ahead forecasts from the two datasets. Overall, the economic value of the forecasts tends to improve with the forecast horizon, especially for developed countries. For developed countries, the DV statistics increases with the forecast horizon for 6 out of 10 countries (Denmark, Euro Area, New Zealand, Norway, Sweden, and the U.K.) in Consensus Economics, and for all 10 countries in FX4Casts. For developing countries, the DV improves with the forecast horizon for 6 out of 23 countries (Chile, Israel, Mexico, Singapore, South Africa, and Taiwan) in Consensus Economics, and for all countries except Brazil, Egypt, and Peru in FX4Casts.

At the 3-month horizon, Consensus Economics forecasts produce higher DV statistics than the forecasts from FX4casts for all developed countries and for 22 out of 23 developing countries (except for Peru). Therefore, Consensus Economics forecasts are more successful in the short run. At the 12-month ahead horizon, the DV statistics of FX4casts forecasts increase for all advanced countries and for 20 out of 23 developing countries (except for Brazil, Egypt, and Peru). However, there is less

\begin{tabular}{|c|c|c|c|c|c|c|c|c|c|c|}
\hline \multicolumn{5}{|c|}{ Forecast horizon $h=3$} & \multicolumn{4}{|l|}{$h=12$} & \multirow{2}{*}{\multicolumn{2}{|c|}{$\begin{array}{l}h=24 \\
\text { Consensus }\end{array}$}} \\
\hline \multirow[b]{2}{*}{ Country } & \multicolumn{2}{|c|}{ Consensus } & \multicolumn{2}{|c|}{ FX4casts } & \multicolumn{2}{|c|}{ Consensus } & \multicolumn{2}{|c|}{ FX4casts } & & \\
\hline & $D V$ & Sharpe Ratio & $D V$ & Sharpe Ratio & DV & Sharpe Ratio & DV & Sharpe Ratio & DV & Sharpe Ratio \\
\hline \multicolumn{11}{|c|}{ A. Developed countries } \\
\hline Australia & 0.204 & -0.064 & 0.130 & 0.057 & 0.163 & -0.024 & 0.220 & 0.185 & 0.226 & -0.029 \\
\hline Canada & 0.179 & -0.037 & 0.132 & 0.080 & 0.166 & 0.287 & 0.256 & 0.406 & 0.172 & 0.240 \\
\hline Denmark & 0.200 & 0.046 & 0.154 & 0.063 & 0.260 & 0.414 & 0.315 & 0.285 & 0.411 & 0.685 \\
\hline Euro Area & 0.192 & 0.068 & 0.152 & 0.142 & 0.258 & 0.384 & 0.317 & 0.297 & 0.406 & 0.681 \\
\hline Japan & 0.290 & -0.042 & 0.130 & -0.194 & 0.305 & -0.276 & 0.230 & -0.226 & 0.254 & -0.003 \\
\hline New Zealand & 0.183 & 0.014 & 0.117 & -0.022 & 0.240 & 0.066 & 0.179 & 0.157 & 0.448 & 0.099 \\
\hline Norway & 0.222 & 0.095 & 0.107 & 0.098 & 0.308 & 0.664 & 0.257 & 0.472 & 0.350 & 0.628 \\
\hline Sweden & 0.229 & 0.021 & 0.109 & 0.088 & 0.338 & 0.548 & 0.254 & 0.399 & 0.434 & 0.606 \\
\hline Switzerland & 0.256 & 0.012 & 0.135 & 0.005 & 0.312 & 0.113 & 0.279 & -0.090 & 0.270 & 0.030 \\
\hline U.K. & 0.204 & 0.204 & 0.157 & 0.069 & 0.232 & 0.591 & 0.312 & 0.437 & 0.280 & 0.784 \\
\hline \multicolumn{11}{|c|}{ B. Developing countries } \\
\hline Argentina & 0.773 & 0.508 & 0.361 & 0.253 & 1.054 & 0.942 & 0.550 & 0.547 & 1.009 & 1.559 \\
\hline Bangladesh & 0.863 & 0.348 & 0.404 & 0.439 & 0.787 & 0.834 & 0.524 & 0.911 & 0.890 & 1.017 \\
\hline Bolivia & 0.394 & -0.371 & 0.285 & 0.379 & 0.282 & -0.546 & 0.476 & 0.046 & 0.305 & -0.858 \\
\hline Brazil & 0.188 & -0.113 & 0.096 & -0.014 & 0.094 & -0.132 & 0.091 & -0.297 & 0.169 & -0.521 \\
\hline Chile & 0.159 & 0.086 & 0.121 & 0.179 & 0.162 & 0.035 & 0.222 & 0.145 & 0.193 & -0.340 \\
\hline Colombia & 0.217 & -0.041 & 0.114 & 0.179 & 0.176 & -0.110 & 0.185 & 0.038 & 0.212 & -0.689 \\
\hline Egypt & 0.645 & -0.224 & 0.534 & 0.155 & 0.409 & -0.163 & 0.499 & 0.062 & 0.376 & 0.000 \\
\hline India & 0.176 & 0.072 & 0.143 & -0.031 & 0.148 & -0.113 & 0.201 & -0.246 & 0.138 & -0.073 \\
\hline Indonesia & 0.175 & -0.077 & 0.108 & -0.011 & 0.170 & 0.121 & 0.154 & -0.132 & 0.303 & 0.380 \\
\hline Israel & 0.186 & -0.160 & 0.081 & -0.115 & 0.200 & 0.046 & 0.082 & -0.616 & 0.210 & -0.176 \\
\hline Mexico & 0.223 & 0.074 & 0.111 & -0.052 & 0.277 & 0.326 & 0.203 & 0.142 & 0.336 & 0.478 \\
\hline Nigeria & 0.525 & -0.072 & 0.226 & 0.156 & 0.289 & 0.093 & 0.330 & 0.193 & 0.432 & 0.260 \\
\hline Pakistan & 0.828 & 0.483 & 0.411 & 0.458 & 0.806 & 0.828 & 0.469 & 0.755 & 0.679 & 1.147 \\
\hline Paraguay & 0.333 & -0.144 & 0.107 & 0.152 & 0.324 & -0.328 & 0.144 & -0.399 & 0.219 & -0.793 \\
\hline Peru & 0.163 & -0.204 & 0.284 & 0.138 & 0.069 & -0.437 & 0.268 & -0.421 & 0.053 & -0.624 \\
\hline Philippines & 0.268 & -0.116 & 0.173 & 0.230 & 0.178 & -0.266 & 0.276 & 0.191 & 0.128 & -0.342 \\
\hline Singapore & 0.299 & 0.129 & 0.156 & 0.107 & 0.364 & 0.377 & 0.368 & 0.537 & 0.407 & 1.275 \\
\hline South Africa & 0.259 & 0.223 & 0.112 & 0.091 & 0.325 & 0.347 & 0.213 & 0.263 & 0.554 & 0.662 \\
\hline South Korea & 0.243 & 0.103 & 0.148 & 0.032 & 0.347 & 0.041 & 0.238 & -0.094 & 0.305 & 0.019 \\
\hline Taiwan & 0.278 & 0.088 & 0.180 & 0.037 & 0.423 & 0.245 & 0.407 & 0.170 & 0.727 & 0.551 \\
\hline Thailand & 0.242 & -0.089 & 0.094 & -0.160 & 0.189 & 0.180 & 0.196 & 0.211 & 0.258 & 0.614 \\
\hline Uruguay & 0.211 & -0.149 & 0.130 & -0.083 & 0.215 & -0.406 & 0.146 & -0.535 & 0.168 & -0.932 \\
\hline Vietnam & 0.641 & 0.344 & 0.409 & 0.422 & 0.577 & 0.653 & 0.548 & 0.977 & 0.389 & 0.898 \\
\hline
\end{tabular}

Table 9

Economic evaluation of survey forecasts.

Notes: The table reports the Directional Value (DV) statistics to measure the economic value of survey forecasts and the Sharpe Ratio to measure the riskadjusted annualized returns of exchange rate forecasts. Sharpe ratios above 0 are marked in bold to indicate forecasts that are successful at generating economic value relative to zero return benchmark. The column "Consensus" shows the results for Consensus Economics dataset, and the column "FX4Casts" contain the results for FX4Casts dataset. The sample covers the period from January 2004 to December 2012. 
improvement in the DV statistics for Consensus Economics forecasts. Consensus Economics forecasts produce higher DV statistics than the forecasts from FX4casts for 5 out of 10 developed countries (Japan, New Zealand, Norway, Sweden, and Switzerland) and for 13 out of 23 developing countries. At the 24-month horizon, the DV statistics increase for 8 out of 10 developed countries (except for Japan and Switzerland), and for 13 out of 23 developing countries in Consensus Economics.

The benchmark for calculating the Sharpe ratios of the exchange rate forecasts is a zero return, meaning that investors do not take any position in the foreign exchange market. Therefore, the survey forecasts that have Sharpe ratios greater than 0 are considered to be successful. In contrast to the results with the DV statistics, FX4casts performs better relative to Consensus Economics at the 3-month horizon. Sharpe ratios are positive for 7 out of 10 developed countries and for 11 out of 23 developing countries in Consensus Economics, and for 8 out of 10 developed countries and for 16 out of 23 developing countries in FX4casts.

At the 12-month ahead horizon, the Sharpe ratios of Consensus Economics forecasts improve both for advanced and developing countries. Positive statistics are found for 8 out of 10 developed countries and for 14 out of 23 developing countries. However, the total number of positive Sharpe ratios in FX4Casts stays the same for developed countries ( 8 out of 10 countries), and slightly decreases for developing countries (15 out of 23 countries) in FX4casts. At the 24-month horizon, the number of positive Sharpe ratios for developed countries does not change ( 8 out of 10 countries) but slightly decreases for developing countries (12 out of 23 countries) in Consensus Economics.

\subsection{Summary of the results}

We have reported the results on rationality, predictive accuracy, and economic value for the two datasets of professional exchange rate forecasts that contain 33 currencies each. Table 10 summarizes the number of significant statistics for each

Table 10

Summary of the results for rationality and predictive accuracy tests.

\begin{tabular}{|c|c|c|c|c|c|}
\hline & \multicolumn{3}{|c|}{ Consensus economics } & \multicolumn{2}{|c|}{ FX4Casts } \\
\hline & $h=3$ & $h=12$ & $h=24$ & $h=3$ & $h=12$ \\
\hline \multicolumn{6}{|l|}{ A. Developed countries } \\
\hline \multicolumn{6}{|l|}{ Rationality tests } \\
\hline Unbiasedness Test & 10 & 5 & 9 & 9 & 3 \\
\hline Orthogonality Test 1 & 3 & 8 & 5 & 1 & 9 \\
\hline Orthogonality Test 2 & 9 & 4 & 7 & 1 & 7 \\
\hline \multicolumn{6}{|c|}{ Predictive accuracy tests } \\
\hline MSPE Ratio < 1 & 0 & 7 & 6 & 0 & 7 \\
\hline DMW Test & 0 & 6 & 6 & 0 & 4 \\
\hline $\mathrm{PCS}>0.5$ & 6 & 7 & 8 & 4 & 9 \\
\hline PT Test & 1 & 9 & 7 & 0 & 6 \\
\hline Number of countries & 10 & 10 & 10 & 10 & 10 \\
\hline \multicolumn{6}{|l|}{ B. Developing countries } \\
\hline Unbiasedness Test & 19 & 17 & 18 & 18 & 15 \\
\hline Orthogonality Test 1 & 16 & 13 & 19 & 2 & 13 \\
\hline Orthogonality Test 2 & 20 & 10 & 15 & 3 & 7 \\
\hline \multicolumn{6}{|c|}{ Predictive accuracy tests } \\
\hline MSPE Ratio < 1 & 4 & 11 & 11 & 7 & 10 \\
\hline DMW Test & 1 & 5 & 10 & 5 & 6 \\
\hline PCS $>0.50$ & 11 & 12 & 12 & 16 & 16 \\
\hline PT Test & 4 & 2 & 3 & 1 & 3 \\
\hline Number of countries & 23 & 23 & 23 & 23 & 23 \\
\hline \multicolumn{6}{|l|}{ C. All countries } \\
\hline \multicolumn{6}{|l|}{ Rationality tests } \\
\hline Unbiasedness Test & 29 & 22 & 27 & 27 & 25 \\
\hline Orthogonality Test 1 & 19 & 21 & 24 & 3 & 22 \\
\hline Orthogonality Test 2 & 29 & 14 & 22 & 4 & 14 \\
\hline \multicolumn{6}{|c|}{ Predictive accuracy tests } \\
\hline MSPE Ratio $<1$ & 4 & 18 & 17 & 7 & 17 \\
\hline DMW Test & 1 & 11 & 16 & 5 & 10 \\
\hline PCS $>0.50$ & 17 & 19 & 20 & 20 & 25 \\
\hline PT Test & 5 & 11 & 10 & 1 & 9 \\
\hline Number of countries & 33 & 33 & 33 & 33 & 33 \\
\hline
\end{tabular}

Notes: The first three rows in Panels A-C report the number of significant rejections of the joint null of unbiasedness and orthogonality (at the $10 \%$ significance level or higher). "Orthogonality Test 1" and "Orthogonality Test 2" denote the tests of orthogonality of the forecast errors to lagged forecast errors and to lagged actual exchange rate depreciation, respectively. The last five rows in Panels A and B report the number of MSPE ratios less than one, the number of significant DMW statistics, the number of proportions of correctly signed forecasts above 0.50 , the number of significant PT statistics (at the $10 \%$ significance level or higher), and the overall number of countries in each group. In Panel A, all the cells have 10 possible rejections. In Panel B, all the cells have 23 possible rejections. In Panel C, all the cells have 33 possible rejections. The sample covers the period from January 2004 to December 2012. 
Summary of the results for economic evaluation of survey forecasts.

\begin{tabular}{|c|c|c|c|c|c|}
\hline & \multicolumn{3}{|c|}{ Consensus economics } & \multicolumn{2}{|c|}{ FX4Casts } \\
\hline & $h=3$ & $h=12$ & $h=24$ & $h=3$ & $h=12$ \\
\hline \multicolumn{6}{|c|}{ A. Developed countries } \\
\hline DV & 0.216 & 0.258 & 0.325 & 0.132 & 0.262 \\
\hline Sharpe ratio & 0.032 & 0.277 & 0.372 & 0.039 & 0.232 \\
\hline Sharpe ratio $>0$ & 7 & 8 & 8 & 8 & 8 \\
\hline \multicolumn{6}{|c|}{ B. Developing countries } \\
\hline Directional Value & 0.360 & 0.342 & 0.368 & 0.208 & 0.295 \\
\hline Sharpe Ratio & 0.030 & 0.112 & 0.115 & 0.128 & 0.106 \\
\hline Sharpe Ratio $>0$ & 11 & 14 & 12 & 16 & 15 \\
\hline \multicolumn{6}{|l|}{ C. All countries } \\
\hline DV & 0.317 & 0.317 & 0.355 & 0.185 & 0.285 \\
\hline Sharpe ratio & 0.031 & 0.165 & 0.224 & 0.099 & 0.149 \\
\hline Sharpe ratio $>0$ & 18 & 22 & 20 & 24 & 23 \\
\hline
\end{tabular}

Notes: The table reports the means of the economic evaluation statistics for FX4Casts and Consensus Economics 3-12-, and 24-month forecasts. "DV" and "Sharpe Ratio" denote the means of the Directional Value and Sharpe ratio, respectively. The row "Sharpe Ratio $>0$ " reports the number of countries with Sharpe ratios greater than 0 in each group. Panel A reports the summary statistics for developing countries, Panel B for developing countries, and Panel C for all countries. The sample covers the period from January 2004 to December 2012.

dataset. Panel A contains the results for developed countries, Panel B for developing countries, and Panel C for all currencies in each dataset. The first three rows in each panel report the number of times the joint null hypothesis of unbiasedness or orthogonality is rejected at least at the 10 percent significance level. "Orthogonality Test 1 " is the test for orthogonality of the forecast errors to the lagged forecast errors, and "Orthogonality Test 2" is the test for orthogonality of the forecast errors to the past exchange rate changes. Smaller number of rejections indicates stronger evidence for rationality of exchange rate expectations. The next four rows summarize the results of the predictive accuracy tests: the number of MSPE ratios below 1 , the number of significant DMW statistics, the number of proportions of correctly signed forecasts above 0.50 , and the number of significant PT statistics (at least at the 10 percent significance level). The last row in each panel is the total number of countries in each group. Therefore, the maximum number of rejections would be 10 for the cells in Panel A, 23 for the cells in Panel B, and 33 for the cells in Panel C.

Overall, we find strong evidence against the unbiasedness of expectations at the 3-month ahead forecast horizon. As the forecast horizon increases to 12 months, the bias in the exchange rate forecasts sharply decreases for developed countries, while the forecast bias stays virtually the same for developing countries. At the 24-month horizon, the unbiasedness hypothesis is strongly rejected again for 9 out of 10 developed countries and 18 out of 23 developing countries.

The results of orthogonality tests are very different with Consensus Economics and FX4Casts. Since the results are clearer for FX4Casts, we summarize them below. Based on both tests, we find strong evidence of forecast efficiency at the short forecast horizon. As the horizon increases to 12 months, we find strong evidence against rationality of forecasts for developed countries and relatively weaker evidence against rationality for developing countries.

The predictive accuracy tests show that the forecasting ability of forecasters increases with the forecast horizon. While there is no significant evidence of short-term predictability based on the DMW statistics for developed countries and weak evidence of predictability for developing countries, the evidence of forecasting accuracy is much stronger at the 12 and $24-$ month horizon. While the forecasters are better at predicting the direction of change for developed countries, they are more successful at predicting the magnitude of the exchange rate change for developing countries.

Table 11 summarizes the results for the economic value of survey expectations. The table reports the means of the DV statistics and Sharpe ratios, and the number of countries with the Sharpe Ratios greater than 0 in each group. Panel A reports the summary statistics for developing countries, Panel B for developing countries, and Panel C for all countries. Three observations are apparent from the results. Fist, positive Sharpe ratios for the majority of developed and developing countries (at least with FX4Casts data) indicate that the forecasters are successful relative to zero return forecast. Second, the mean directional value is larger for developing countries than developed countries. Third, both measures of economic value for developed countries increase on average with the forecast horizon.

\section{Conclusions}

We examine the rationality, predictive accuracy, and economic value of survey-based exchange rate forecasts for 10 developed and 23 developing countries in Consensus Economics and FX4Casts datasets from January 2004 to December 2012. For developing countries, the null of unbiasedness is strongly rejected at the 3-, 12-, and 24-month horizons. For developed countries, we find strong evidence that the forecasts are biased at the short horizon. The results indicate that increasing the forecast horizon has a non-linear effect on the unbiasedness of survey forecasts for developed countries. The forecast bias 
sharply decreases at the 12-month horizon, but rises again at the 24-month horizon. Interestingly, professional forecasters in FX4Casts are very efficient at the short forecast horizon based on the two orthogonality criteria. As the horizon increases to 12 months, forecast efficiency is strongly rejected for developed countries, while the forecasts for developing countries are relatively more efficient.

Using the tests based on the MSPE and directional accuracy comparison, we find that the forecasting performance is stronger for developed countries. The evidence of forecasting ability is poor at the short horizon, which is consistent with Jongen et al. (2008) who summarize the studies that evaluate the accuracy of survey-based exchange rate forecasts and conclude that "the random walk model remains pre-eminent." The evidence of forecasting ability improves significantly at longer horizons. This result is in line with the empirical finding in Mark (1995), Engel et al. (2008), and Ince (2014) among others that the evidence of exchange rate predictability is stronger at longer forecast horizons. Also, directional accuracy of survey forecasts for developed countries is better at longer horizons, however, for developing countries the directional accuracy does not improve over longer forecast horizons.

We assess the economic value of the forecasts based on the Directional Value statistic developed by Blaskowitz and Herwartz (2011) and the Sharpe Ratio. The results indicate that the forecasters are successful at generating positive economic profits. The mean directional value is larger for developing than developed countries at all forecast horizons. As with the statistical evaluation of the forecast accuracy, both economic value statistics for developed countries increase on average with the forecast horizon. Overall, survey-based forecasts are more successful based on the economic evaluation than statistical evaluation, especially for FX4Casts. This result is not surprising, considering the focus of FX4Casts on large financial institutions, whose objective is generating economic profits.

Overall, our analysis indicates that exchange rate forecasts are not rational. There are several future avenues of research on empirical evaluation of open-economy models that assume rational expectation hypothesis. First, these models can be reevaluated using survey-based expectations as a proxy for market expectations instead of ex-post actual exchange rates. Second, further study of the nature of exchange rate expectation formation mechanisms could help to improve our understanding of the exchange rate models. Additionally, the results suggest that statistical inference methodology can be effectively complemented by economic evaluation of survey-based exchange rate forecasts, which can capture important aspects of the market participants' behavior. Future research in this direction might reveal the details about the models that forecasters are using to produce economic gains.

\section{Acknowledgements}

We thank Olivier Coibion, Iordanis Petsas, Tatevik Shekhposyan, and participants at presentations at the Southern Economics Association Meetings 2015, Western Economic Association Meetings 2014, Canadian Economic Association Meetings 2013, and Appalachian State University for helpful comments and discussions. We also thank Alan Teck at FX4Casts for helpful suggestions and interpretations of the data. We are grateful for the financial assistance from the Walker College of Business at the Appalachian State University and Emory University that supported this study.

\section{References}

Aiolfi, Marco, Capistran, Carlos, Timmermann, Allan, 2011. Forecast combinations. In: Clements, Michael P., Hendry, David F. (Eds.), The Oxford Handbook of Economic Forecasting. Oxford.

Avraham, David, Ungar, Meyer, Zilberfarb, Ben-Zion, 1987. Are foreign exchange forecasts rational? An empirical note. Econ. Lett. 24, $291-293$.

Bank for International Settlements, February 2014. Triennial Central Bank Survey Global Foreign Exchange Market Turnover in 2013, <http://www.bis.org/ publ/rpfxf13fxt.pdf> (Last accessed on 10/17/2016).

Bansal, Ravi, Dahlquist, Magnus, 2000. The forward premium puzzle: different tales from developed and emerging economies. J. Int. Econ. 51, 115-144. Bénassy-Quéré, Agnès, Larribeaub, Sophie, MacDonald, Ronald, 2003. Models of exchange rate expectations: how much heterogeneity? J. Int. Financ. Markets Inst. Money 13, 113-136.

Blaskowitz, Oliver, Herwartz, Helmut, 2011. On economic evaluation of directional forecasts. Int. J. Forecast. 27, 1058-1065.

Bonham, Carl S., Cohen, Richard H., 2001. To aggregate, pool, or neither: testing the rational-expectations hypothesis using survey data. J. Bus. Econ. Stat. 19, $278-293$.

Cavaglia, Stefano, Verschoor, Willem F.C., Wolff, Christian C.P., 1993. Further evidence on exchange rate expectations. J. Int. Money Finance 12, 78-98.

Cavusoglu, Nevin, Neveu, Andre, 2015. The predictive power of survey-based exchange rate forecasts: is there a role for dispersion? J. Forecast. $34,337-353$.

Chinn, Menzie, 2006. The (partial) rehabilitation of interest rate parity in the floating rate era: longer horizons, alternative expectations, and emerging markets. J. Int. Money Finance 26, 7-21.

Chinn, Menzie, Frankel, Jeffrey, 1994. Patterns in exchange rate forecasts for 25 currencies. J. Money Credit Bank. 26, 759-770.

Chinn, Menzie, Frankel, Jeffrey, 2002. Survey data on exchange rate expectations: more currencies, more horizons, more tests. In: Allen, W.. Dickinson, D.

(Eds.), Monetary Policy, Capital Flows and Financial Market Developments in the Era of Financial Globalization: Essays in Honour of Max Fry. Routledge, London, pp. 145-167.

Clark, Todd, West, Kenneth, 2006. Using out-of-sample mean squared prediction errors to test the martingale difference hypothesis. J. Economet. 135, 155186.

Diebold, Francis, Mariano, Robert, 1995. Comparing predictive accuracy. J. Bus. Econ. Stat. 13, 253-263.

Dreger, Christian, Stadtmann, Georg, 2008. What drives heterogeneity in foreign exchange rate expectations: insights from a new survey. Int. J. Finance Econ. 13, 360-367.

Dominguez, Kathryn M., 1986. Are foreign exchange forecasts rational? New evidence from survey data. Econ. Lett. 21, 277-281.

Elliott, Graham, Ito, Takatoshi, 1999. Heterogeneous expectations and tests of efficiency in the yen/dollar forward exchange rate market. J. Monetary Econ. 43, 435-456.

Engel, Charles, 1996. The forward discount anomaly and the risk premium: a survey of recent evidence. J. Empirical Finance 3, 123-192.

Engel, Charles, Mark, Nelson C., West, Kenneth D., 2008. Exchange rate models are not as bad as you think. In: NBER Macroeconomics Annual 2007. University of Chicago Press, Chicago, IL, pp. 381-441. 
Frankel, Jeffrey, Froot, Kenneth, 1987. Using survey data to test standard propositions regarding exchange rate expectations. Am. Econ. Rev. 77 (1). Reprinted in Frankel, On Exchange Rates, MIT Press, 1993, 133-153.

Frankel, Jeffrey, Poonawala, Jumana, 2010. The forward market in emerging currencies: less biased than in major currencies. J. Int. Money Finance 29, 585598.

Frankel, Jeffrey, Chinn, Menzie, 1993. Exchange rate expectations and the risk premium: tests for a cross-section of 17 currencies. Rev. Int. Econ. 1, $136-144$. Gençay, Ramazan, 1998. The predictability of security returns with simple technical trading rules. J. Emp. Finance 5, 347-359.

Jongen, Ron, Willem, F.C., Verschoor, Christian, C.P., Wolff, 2008. Foreign exchange rate: survey and synthesis. J. Econ. Surv. 22, 140-165.

Ince, Onur, 2014. Forecasting exchange rates out-of-sample with panel methods and real-time data. J. Int. Money Finance 43 , 1-18.

Ito, Takatoshi, 1990. Foreign exchange rate expectations: micro survey data. Am. Econ. Rev. 80, 434-449.

Keane, Michael P., Runkle, David E., 1990. Testing the rationality of price forecasts: new evidence from panel data. Am. Econ. Rev. $80,714-735$.

Lewis, Karen K., 1995. Puzzles in international financial markets. In: Grossman, Gene, Rogoff, Kenneth (Eds.), Handbook of International Economics. Elsevier Science, pp. 1913-1971.

MacDonald, Ronald, 2000. Expectations formation and risk in three financial markets: surveying what the surveys say. J. Econ. Surv. 14, 69-100.

MacDonald, Ronald, Marsh, Ian W., 1994. Combining exchange rate forecasts: what is the optimal consensus measure? Int. J. Forecast. 13, 313-332.

MacDonald, Ronald, Marsh, Ian W., 1996. Currency forecasters are heterogeneous: confirmation and consequences. J. Int. Money Finance 15, 665-685.

MacDonald, Ronald, Torrance, Thomas S., 1990. Expectations formation and risk in four foreign exchange rate markets. Oxford Econ. Papers 42, 544-561.

Mark, Nelson, 1995. Exchange rate and fundamentals: evidence on long-horizon predictability. Am. Econ. Rev. 85, $201-218$.

Meese, Richard A., Rogoff, Kenneth, 1983. Empirical exchange rate models of the seventies: do they fit out of sample? J. Int. Econ. $14,3-24$.

Mitchell, Karlyn, Pearce, Douglas, 2007. Professional forecasts of interest rates and exchange rates: evidence from the Wall Street Journal's panel of economists. J. Macroecon. 29, 840-854.

Muth, Richard A., 1961. Rational expectations and the theory of price movements. Econometrica 29, 315-335.

Pesaran, Hashem M., 1987. The Limits to Rational Expectations. Basil Blackwell, Oxford.

Pesaran, M. Hashem, Timmermann, Allan, 1992. A simple nonparametric test of predictive performance. J. Bus. Econ. Stat. $10,561-565$.

Rossi, Barbara, 2013. Exchange rate predictability. J. Econ. Lit. 51, 1063-1119.

Takagi, Shinji, 1991. Exchange rate expectations: a survey of survey studies. IMF Staff Papers 38, 156-183.

West, Kenneth D., 1996. Asymptotic inference about predictive ability. Econometrica 64, 1067-1084. 